\title{
Tethyan collision forces and the stress field of the Eurasian Plate
}

\author{
Karin N. Warners-Ruckstuhl, ${ }^{*}$ Rob Govers and Rinus Wortel \\ Department of Earth Sciences, Utrecht University, P.O. Box 80.021, 3508 TA Utrecht, The Netherlands. E-mail: karin.warners@shell.com
}

Accepted 2013 May 29. Received 2013 May 8; in original form 2012 November 20

\begin{abstract}
SUMMAR Y
Resistive forces along convergent plate boundaries have a major impact on surface deformation, most visibly at collisional plate boundaries. Although quantification of these forces is key to understanding the evolution and present state of mountain belts, they remain highly uncertain due to the complexity of plate boundary structures and rheologies. In previous studies of the Eurasian Plate, we have analysed the balance of plate boundary forces, tractions resulting from lithosphere-mantle coupling, and intraplate variations in topography and density structure. This yielded a range of acceptable force distributions. In this study, we investigate to which extent the observed present-day stress field provides further constraints on the distribution of forces.

We address the dynamics of the Eurasian Plate as a whole. This enables us to base our analysis on mechanical equilibrium of a tectonic plate and to evaluate all forces as part of an internally consistent set of forces driving and deforming Eurasia. We incorporate tractions from convective mantle flow modelling in a lithospheric model in which edge and lithospheric body forces are modelled explicitly and compute resulting stresses in a homogeneous elastic thin shell. Intraplate stress observations used are from the World Stress Map project. Eurasia's stress field turns out to be particularly sensitive to the distribution of collision forces on the plate's southern margin and, to a much lesser extent, to lithospheric density structure and tractions from mantle flow. Stress observations require collision forces on the India-Eurasia boundary of $7.0-10.5 \mathrm{TN} \mathrm{m}^{-1}$ and on the Arabia-Eurasia boundary of $1.3-2.7 \mathrm{TN} \mathrm{m}^{-1}$. Implication of mechanical equilibrium of the plate is that forces on the contacts with the African and Australian plates amount to $1.0-2.5$ and $0-1.3 \mathrm{TN} \mathrm{m}^{-1}$, respectively. We use our results to assess the validity of the classical view that the mean elevation of an orogenic plateau can be taken as a measure of the magnitude of the compressive (in this case: collision-related) forces involved. For both the Tibetan and the Iranian plateaus, two plateaus with significantly different average elevations, we find that the horizontal force derived from the excess gravitational potential energy (collapse force) is in balance with the collision force.
\end{abstract}

Key words: Plate motions; Continental margins: convergent; Dynamics of lithosphere and mantle; Dynamics: gravity and tectonics; Neotectonics; Asia; Europe.

\section{INTRODUCTION}

Plate tectonics is driven by gravity and resisted by friction. The gravitational forces can be quantified with increasing certainty as the density structure of the Earth becomes better resolved (Bassin et al. 2000; Simmons et al. 2010). Resistive forces caused by plate interactions, however, remain highly uncertain. The mechanical coupling of plates controls the transmission of forces across plate boundaries. Because plate boundary zones have complex rheologies and structures, significant lateral variations in the degree of coupling are to

\footnotetext{
*Now at: Shell Global Solutions, Kesslerpark 1, 2288 GS, Rijswijk, The Netherlands.
}

be expected. Although computational advances allow for incorporating plate margins in numerical models at an increasingly high resolution (Stadler et al. 2010), the resulting uncertainties hamper the reliable assessment of resistive forces from gravity-driven geodynamic models.

Resistive forces along plate boundaries have a major impact on surface deformation, most visibly at convergent plate boundaries. In this study, we focus on the Eurasian Plate and its southern boundary, the most prominent suture zone on the Earth. It resulted from closure of the Neo-Tethys Ocean (Dercourt et al. 1993; Şengör \& Natal'in 1996; Stampfli \& Borel 2002, 2004; Hafkenscheid et al. 2006) and subsequent continental collision and is home to the highest mountain range on the Earth. Along its length, Eurasia's southern plate boundary displays plate convergence in different stages of evolution, 
from ongoing oceanic lithosphere subduction (Sunda Arc) through fairly recent continental (or arc-continent) collision (Banda Arc, western-central Mediterranean; Carminati et al. 1998; Spakman \& Hall 2010) to mature continental collision (Arabia, India; Molnar \& Tapponnier 1975; Agard et al. 2005; Aitchison et al. 2007; Hinsbergen et al. 2012; Mouthereau et al. 2012). Quantification of the lateral variations in magnitude of the forces along the suture zone is key to understanding the evolution and present state of mountain belts.

In previous studies of the Eurasian Plate (Warners-Ruckstuhl et al. 2010, 2012), we have analysed the balance of plate boundary forces (edge forces), tractions resulting from lithosphere-mantle coupling and intraplate variations in topography and density structure. This yielded a range of acceptable force distributions, satisfying the constraint of Eurasia's absolute plate motion. Here, we investigate to which extent the observed present-day stress field provides further constraints on the distribution of forces, with a particular interest in the distribution of resistive collision-related forces acting along Eurasia's southern boundary.

For Eurasia, plateau elevation is a first-order element along the Tethyan suture zone, representing a scale commensurate with that of our force modelling. By referring to mountain ranges as 'pressure gauges' which are thought to register the horizontal collision forces that prevent them from collapsing, Molnar \& Lyon-Caen (1988) implicitly assumed that collision forces are equal to gradients in gravitational potential energy (GPE) parallel to the convergence direction. We refer to this as the 'balanced topography assumption'. Significant support for this assumption came since the work of Davis et al. (1983), when it was demonstrated that many fold-andthrust belts attained an overall triangular shape that agreed with a balance of driving forces and gravity. The numerical models of Rey \& Houseman (2006), however, support the notion that, under the Earth-like conditions, GPE-derived forces can deviate significantly from collision forces for substantial amounts of time. Using the result of our force analysis on the Eurasian Plate, we will test whether the Iranian and Tibetan plateaus fulfil the balanced topography assumption.

The basis of our analysis is mechanical equilibrium of tectonic plates, which implies that the sum of all torques on a plate vanishes (Forsyth \& Uyeda 1975; Chapple \& Tullis 1977). This approach allows us to solve for the forces transmitted from adjacent plates without the need to make assumptions regarding the ill-constrained rheology and structure of plate boundaries. We use stress observations as compiled in the World Stress Map project (Heidbach et al. 2008) to evaluate the force distributions. Our single-plate approach should enable us to resolve the edge forces with greater detail than has been possible with global-scale models based on uniform coupling across plate boundaries of the same type (Becker \& O'Connell 2001; Bird et al. 2008; Iaffaldano \& Bunge 2009).

Thus far, most studies assessing the forces acting along the Tethys suture zone and resulting stresses have been centred around a specific part of the Eurasian Plate boundary, focusing on the collision with the African (Grünthal \& Stromeyer 1992; Gölke \& Coblentz 1996), the Arabian (Özeren \& Holt 2010) or the Indian Plate (England \& Houseman 1989; Flesch et al. 2001; Vergnolle et al. 2007; Copley et al. 2010). Hieronymus et al. (2008) adopted a box-like model geometry for the Eurasian Plate with an oversimplified force set that is not physically constrained. By addressing the dynamics of the entire Eurasian Plate, we capture the whole suture zone inside a single model and, importantly, obtain an internally consistent force distribution along its length.

\section{FORCE MODELLING METHOD}

The combined lithosphere-mantle approach to force modelling outlined in Warners-Ruckstuhl et al. (2010) and Warners-Ruckstuhl et al. (2012) (hereafter referred to as WR2012) forms the basis for the quantification of collision forces using stress field analysis presented in this study. In this section, we therefore present an account of this method and of the most relevant results of our previous work.

We model the Eurasian Plate as a thin shell with edge forces acting on lateral boundaries (Forsyth \& Uyeda 1975; Warners-Ruckstuhl et al. 2010). Through torque balance, we solve for the magnitudes of the edge forces such that they counterbalance the lithospheric body forces (LBFs) and tractions at the base. For a force distribution including $N_{E}$ edge force types ${ }_{i} \bar{F}_{E}$ (with $\left.i=1, . . N_{E}\right), N_{B}$ LBF types ${ }_{i} \bar{F}_{B}$ and mantle tractions $\bar{F}_{M}$ :

$\sum_{i=1}^{N_{E}} \int_{S} \bar{r} \times{ }_{i} \bar{F}_{E} \mathrm{~d} S+\sum_{i=1}^{N_{B}} \int_{V} \bar{r} \times{ }_{i} \bar{F}_{B} \mathrm{~d} V+\int_{A} \bar{r} \times \bar{F}_{M} \mathrm{~d} A=\overline{0}$

with $S$ the surface area of the plate boundary, $A$ the surface area of the bottom of the plate, $V$ the volume of the plate and $\bar{r}$ the vector from the centre of the Earth to the geographical point where a force is acting.

The contribution of LBFs and mantle tractions to the dynamics of Eurasia is based on physical models as described later. We extend the classical torque-balance approach (Forsyth \& Uyeda 1975; Wortel et al. 1991; Meijer \& Wortel 1992) by representing the interaction of the plate with the underlying mantle by tractions from global mantle flow models driven by the combination of buoyancy forces inside the mantle and imposed plate motion (Ricard \& Vigny 1989).

\subsection{Plate boundaries and edge forces}

Our model for the Eurasian Plate is based on major plate boundaries (Bird 2003) on which plate boundary types can be readily identified. The model domain includes several microplates, for example, in SE Asia, Okinawa, Birma, Aegean and Anatolia. Major internal faults do not affect the torque balance calculations because tractions across internal faults oppose each other and do not generate a net torque. They may, however, affect the transmission of stresses. We will therefore test for their imprint in the discussion Section 6.2.

Edge forces result from mechanical interaction of Eurasia with neighbouring plates. We therefore base the type of forcing on Eurasia's boundaries on tectonic setting (Fig. 1). We distinguish four types of plate boundaries (Fig. 1): (1) ridge and transform boundary (red line), (2) continental collision boundaries (black triangles), (3) trench roll-back margins (including the narrow section showing slab reversal in Taiwan) (blue triangles) and (4) non-roll-back subduction margins (green triangles). The plate boundary between continental North America and Eurasia (black line) is unclassified because neither its exact location nor its nature is very clear as a result of the small relative velocities and the absence of seismicity or recent tectonic features (Chapman \& Solomon 1976). All plate boundaries are associated with specific forces. These forces represent the most relevant contribution of processes at and beyond the domain boundary. Transform fault resistance, continental collision and forces at non-roll-back subduction segments arise from friction at the plate contact and are modelled antiparallel to the direction of motion relative to the adjacent plate (NUVEL-1A; DeMets et al. 1994). Forces at subduction roll-back segments are expected to be dominated by suction of the retreating slab and are modelled 


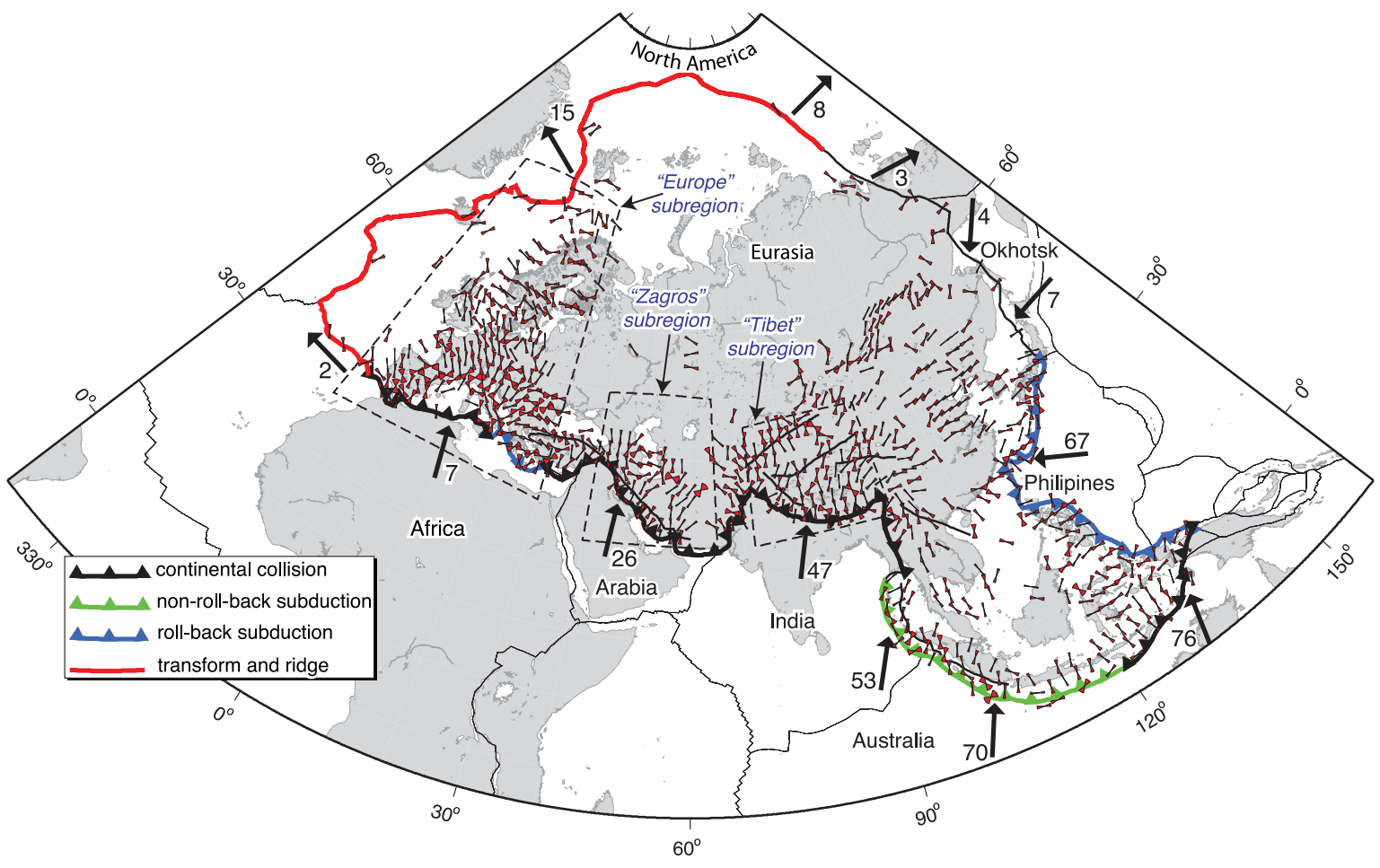

Figure 1. Plate boundary types and internal faults (thin black lines) of our model Eurasian Plate. Arrows denote NUVEL-1A velocities in mm yr ${ }^{-1}$ of adjacent plates. Red fans indicate directions of most compressive horizontal stresses including error margin from averaging World Stress Map observations (see Appendix). Dashed lines enclose subregions in which we separately evaluate model stresses.

outward and perpendicular to the trench. We solve for averages of the force magnitudes via torque balance, that is, we assume these magnitudes to be uniform along similar plate boundary segments. We make an exception for the continental collision boundary, which we divide into separate segments for Africa, Arabia, India and Australia.

\subsection{Mantle tractions}

Mantle tractions are calculated using global mantle flow models driven by tomographically derived buoyancy anomalies and topped by moving plates. We use the graphical user interface SEATREE (Milner et al. 2009) to compute Stokes flow in a radially varying viscous mantle through an implementation of a semi-analytic propagator matrix approach (Hager \& O'Connell 1981) by Becker et al. (2006), based on Steinberger (2000). Shear components of the resulting traction vectors at the base of the lithosphere are directly accounted for. Normal components are accounted for via the LBFs (Hager et al. 1985; Lithgow-Bertelloni \& Silver 1998; WarnersRuckstuhl et al. 2012).

Warners-Ruckstuhl et al. (2012) discuss how uncertainties in mantle tractions arise from (1) the distribution of tomographic anomalies from which we infer buoyancy forces, (2) scaling between velocity and density anomalies ( $v-\rho$ scaling) and (3) mantle viscosity. They show that the last two parameters mainly affect the magnitude of mantle tractions rather than its pattern. This magnitude is constrained by mechanical equilibrium of the Eurasian Plate.

In this study, we only consider mantle flow models that were shown by WR2012 to successfully balance the Eurasian Plate. Active mantle flow in these models is based on $S$-wave tomographic anomalies, and passive mantle flow is induced by plate motions.
Active and passive contributions to the net mantle tractions on the lithosphere turn out to be of comparable magnitudes. Mechanical balance is achieved by fine-tuning the $v-\rho$ scaling and viscosity magnitudes, yet within the uncertainty bounds indicated by mineral physics (see WR2012 for further details).

\subsection{LBFs}

The net horizontal force $\bar{F}$ generated by lateral density variations is the horizontal gradient of the GPE. GPE can be computed when the density structure of the lithosphere is known and is derived from the integrated vertical stress of a lithospheric column (Artyushkov 1973; Fleitout \& Froidevaux 1982; Molnar \& Lyon-Caen 1988):

$F_{x}=\frac{\delta \mathrm{GPE}}{\delta x}, \quad F_{y}=\frac{\delta \mathrm{GPE}}{\delta y} \quad \mathrm{GPE}=\int_{-h}^{L}\left[\int_{-h}^{z} \rho\left(z^{\prime}\right) g \mathrm{~d} z^{\prime}\right] \mathrm{d} z$,

where $z$ is depth ( $z=0$ at sea level), $h$ is topography, $L$ is depth to the base of the reference lithosphere (Fig. 2), $\rho$ is density and $g$ is gravitational acceleration (equation corrected from WR2012.A2). The density structure of oceanic lithosphere is relatively well known, hence oceanic LBFs (largely ridge push) are well constrained. In continental lithosphere the density structure is less well known. Also, normal components of the basal traction from mantle convection influence LBFs by inducing dynamic topography, and have an important impact on the stress field (Steinberger et al. 2001; Lithgow-Bertelloni \& Guynn 2004).

WR2012 develop three alternative LBF models to assess the influence of these uncertainties on the torque from body forces. LBFs (in Newton per square metre surface area) are applied as tractions along the surface of the plane stress finite element model (fig. 5 in WR2012 displays the resulting nodal forces on the [relatively 


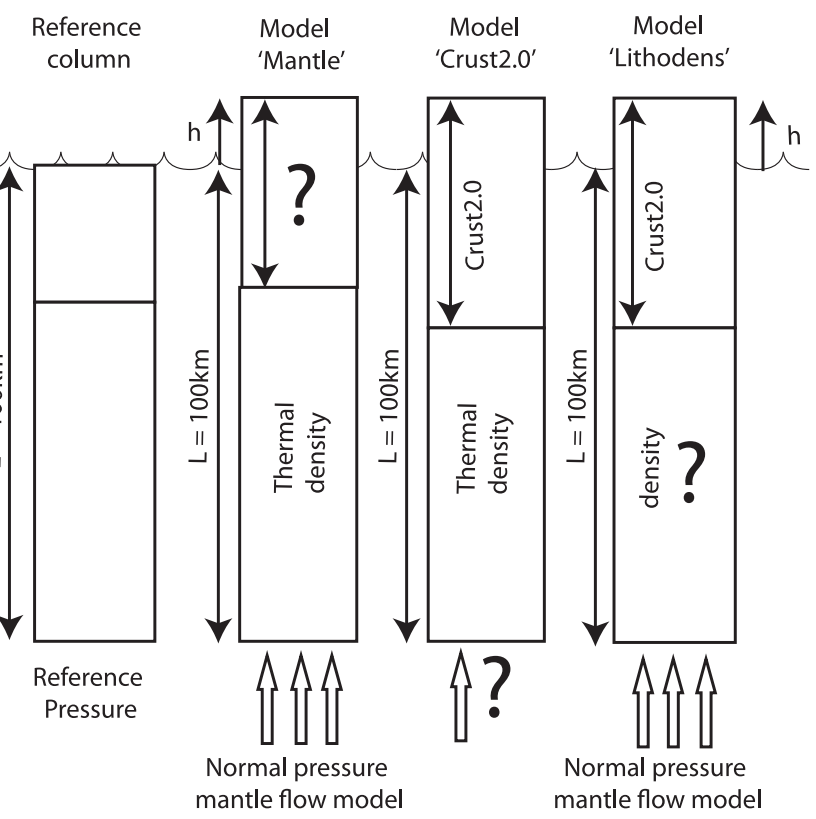

Figure 2. Lithospheric columns illustrating assumptions made in the three LBF models. The question mark in each model represents the quantity that is taken to be unknown (and therefore is calculated) so that the height of the column matches the observed topography. In model Mantle, crustal thickness is taken to be poorly constrained, in model Crust 2.0 normal components of mantle tractions are taken to be unknown and in model Lithodens the weight of the lithospheric mantle is considered to be uncertain.

uniform] finite element grid of equilateral triangles with approximately $50 \mathrm{~km}$ edges). The principal uncertainty is taken to reside in alternative components; in the crust in model Mantle, in the lithospheric mantle in model Lithodens or in the dynamic mantle pressure at the base of the lithosphere (model Crust2.0). Fig. 2 illustrates the main elements of the three models.

LBF model Mantle takes the dynamic topography to be known. Somewhat different from what we assumed for this model in WR2012, we use observed topography and bathymetry (ETOPO1; Amante \& Eakins 2009) as a constraint for the entire domain. The part of the topography that is not dynamically supported is assumed to be isostatically compensated by variations in crustal thickness. We assume a uniform average density for the crust and a temperaturedependent lithospheric density and compute crustal thicknesses that result in the observed topography. LBF model Crust2.0 is based on crustal thicknesses and densities of seismological model Crust2.0 (Bassin et al. 2000) and assumes that deviations from isostatic equilibrium are dynamically supported at the base of the lithosphere. As in model Mantle, the lithospheric mantle density is temperature-dependent (linear geotherm). LBF model Lithodens combines crustal thickness and density from Crust2.0 with normal stresses from mantle flow modelling and assumes that remaining lateral topography variations are caused by density variations within the lithospheric mantle. We calculate averaged densities of the lithospheric mantle so that observed topography is matched (Fig. 2).

\subsection{Torque balance solutions}

Through torque balance, the net torque corresponding with the edge forces is constrained by the integrated contribution of the LBFs and mantle tractions, for which we have quantitative estimates. This edge force torque can, however, result from a range of edge force distributions. We advance beyond the results of WR2012 by discriminating between alternative force distributions by making use of the intraplate stress field.

\section{STRESS MODELLING}

\subsection{General aspects}

The distinct long-wavelength character of the observed stress field (Zoback 1992) suggests a dominant role for plate tectonic forces and transmission of stresses over long distances. A satisfactory model of the forces acting on the lithosphere should therefore explain the principal features of the stress field.

The initial response of rocks to loading is to deform elastically, resulting in stresses that may subsequently drive permanent deformation processes. We focus on constraining the forces generating the lithospheric stress field and restrict ourselves to modelling of the first step: computing elastic stresses. These elastic stresses represent the potential for permanent deformation. The next step of connecting these stresses to kinematic observations (velocities, strain and rotation rates) requires insight into the rheological properties of the lithosphere and is beyond the scope of this paper. Elastic stresses provide an unbiased and simple means to evaluate force models. Although observed stresses have likely been subject to relaxation as a result of permanent deformation, stress directions are not affected by viscous relaxation or slip on a network of randomly oriented faults that isotropically reduce stress magnitudes. Directions of stresses in our models should therefore coincide with observed stresses in most regions. Stress directions are, however, affected by fault slip because relaxation is highly anisotropic in this case. We will therefore test the sensitivity of our results to major faults in our model domain (see Section 6.2).

We compute stress fields in our model Eurasian lithosphere by solving the mechanical equilibrium equations using finite elements in a spherical shell (GTECTON, Govers \& Meijer 2001). Spatial discretization of the model domain was verified to be dense enough that results are insensitive to further grid refinement. Our model is fully elastic with a Young's modulus of $70 \mathrm{GPa}$ and a Poisson's ratio of 0.25 . We solve for the (vertical averages of the) intraplate stress field using a plane stress formulation. Stresses are presented for a uniform reference thickness of $100 \mathrm{~km}$, that is, stress magnitudes have not been adapted for variations in lithospheric thickness.

\subsection{Evaluation of force distributions based on the stress field}

As we will see later, modelled intraplate stresses differ considerably between force sets. We evaluate all force distributions that fulfil the torque balance constraint. We compute misfit angles from observations for each stress model (see Section 4). We structure our analysis in two consecutive steps.

In our first series of models (called EUR1), we explore the range of balanced force sets by solving for individual magnitudes of the collision forces on the combined African/Arabian, the Indian and the Australian Plate contact while systematically varying the magnitudes of the other edge forces. Thereby: (i) we assume that there are no edge forces on the ill-constrained continental boundary with the North American/Okhotsk Plate; (ii) we solve for forces at nonroll-back margins simultaneously with the force on the Australian collisional boundary because the corresponding torques show a trade-off due to their similar orientation. Along the Sunda-Banda arc, force magnitudes on the ocean-continent segment are expected 
to be lower than on the continent-continent segment. We therefore vary force magnitude at the non-roll-back margin between 0.25 and 1 times that of the Australian (Banda) continental collision force. Furthermore, (iii) we vary resistance at oceanic transform boundaries and roll-back margins between values for which we find physically realistic solutions, $0-1 \mathrm{TN} \mathrm{m}^{-1}$ and $0-0.5 \mathrm{TN} \mathrm{m}^{-1}$, respectively. We discuss the overall best-fitting EUR1 model (EUR1best) and analyse the average misfit angle as a function of edge forces, LBFs and mantle tractions. This sensitivity analysis enables us to see that the regional model fit can be improved, meaning that the observations require us to adopt regional variability in the forcing not included in the EUR1 models. This serves as the basis for the second step of our analysis, in which we refine the edge force distribution by readdressing some of our assumptions and build a next series of force models (EUR2) (Section 6.1).

\section{STRESS OBSERVATIONS}

The World Stress Map 2008 data release (WSM; Heidbach et al. 2008) provides information on the current stress field, obtained from various sources including earthquake focal mechanisms, borehole breakouts and geological field observations of recent and active faulting. The data are limited to horizontal stress directions. In the present database, there is no depth information and we take the data to represent depth-averaged stress directions. The data coverage is highly uneven in Eurasia; Europe, the whole southern boundary, the Tibetan Plateau and the Baikal region are relatively densely sampled whereas extensive parts of central Asia lack any indicators.

We evaluate stress models based on a combination of plate-wide and regional averaged misfits (see Fig. 1 for indication of the regions used). To prevent regions with many observations to dominate misfit averages, we average directions of most compressive horizontal principal stress $\left(S_{\mathrm{Hmax}}\right)$ over $2^{\circ} \times 2^{\circ}$ intervals. The chosen interval size does affect the mean observed stress direction, but we verified that alternate choices of the averaging interval do not affect our conclusions. Appendix details how we compute the mean observed stress direction and the associated error. It is based on uncertainties in the individual stress directions and on the spread in the data in an interval. Results are displayed in Fig. 1. Average errors in the observations are $25^{\circ}$ for the whole plate, $35^{\circ}$ within subregion Europe, $24^{\circ}$ within subregion Zagros and $24^{\circ}$ within subregion Tibet.

Essentially, a model predicted stress direction fits an observation well if it matches the data within the error margin of the data. In the results below, we present mismatch angles as the difference between the model and the mean of the data in combination with the mean error in the data. This is thus a more severe measure of model misfit.

\section{RESULTS}

\subsection{Stress field for best-fitting EUR1 model}

Stress results within the EUR1 class of models differ most strongly in the Tibetan Plateau area. The overall best performing model (EUR1best) is based on LBFs from model Lithodens with basal tractions from a mantle flow model based on tomographic model ngrand (Grand 2002, converted to densities using a constant scaling factor of 0.18 ; see Section 2.2), and the radial viscosity profile of Mitrovica \& Forte (2004). Collision forces along the southern boundary from Gibraltar to Myanmar are the most dominant edge forces (inset of Fig. 3). Forces on the Indian collision segment are nearly twice as high as on the African and Arabian segments. Forces along the Sunda and Banda arc are negligible. The resulting stress field (Fig. 3) shows nearly uniaxial compression in large parts of Europe and western Asia caused by the interaction between collision forces and ridge push. Average stress magnitudes are typically of the order of $50 \mathrm{MPa}$. The model Tibetan Plateau is in an overall state of extension because gravitational collapse forces dominate

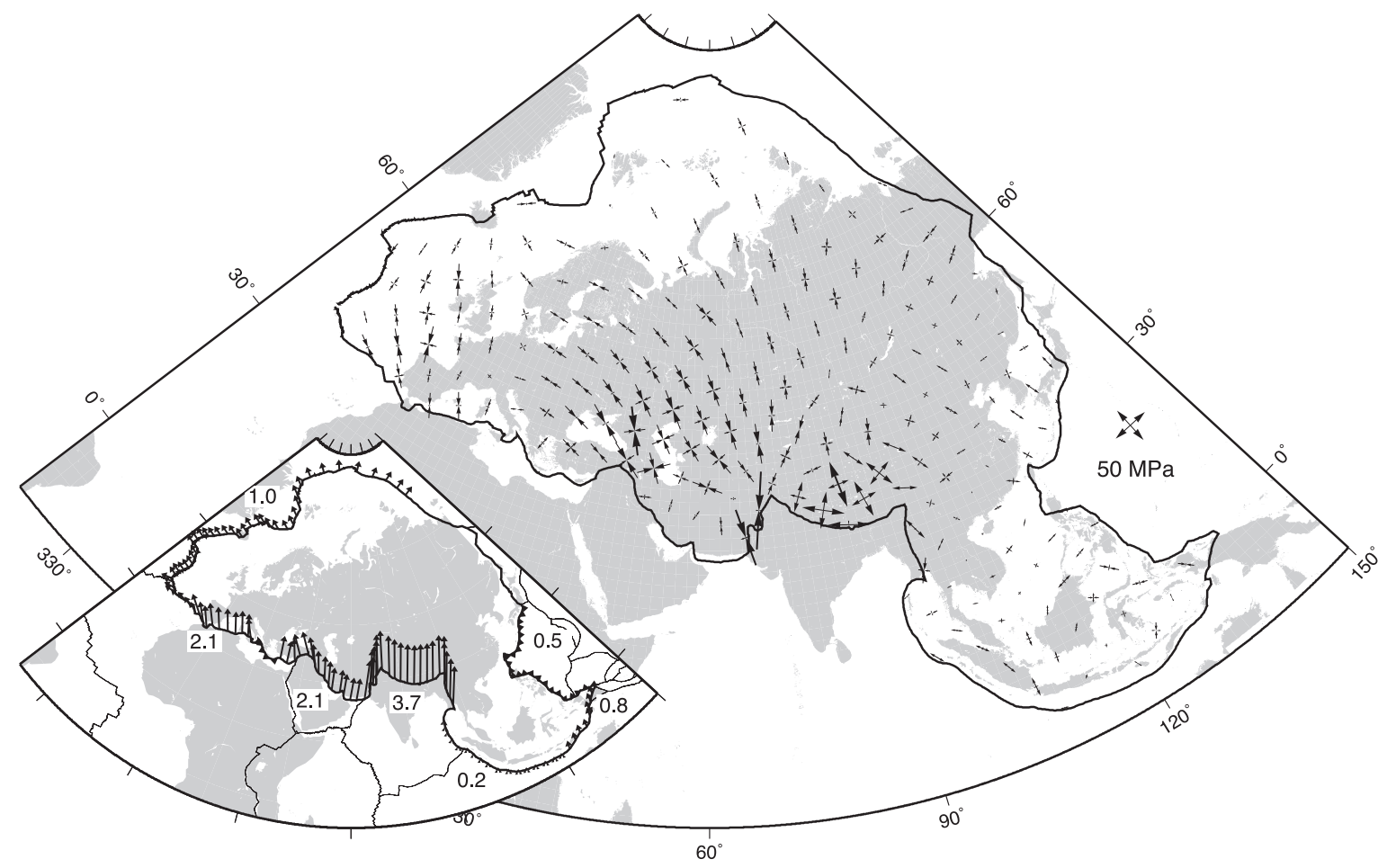

Figure 3. Stress field for force model EUR1best. Corresponding edge forces are displayed in the inset; numbers are average magnitudes in $\mathrm{TN} \mathrm{m}^{-1}$. 


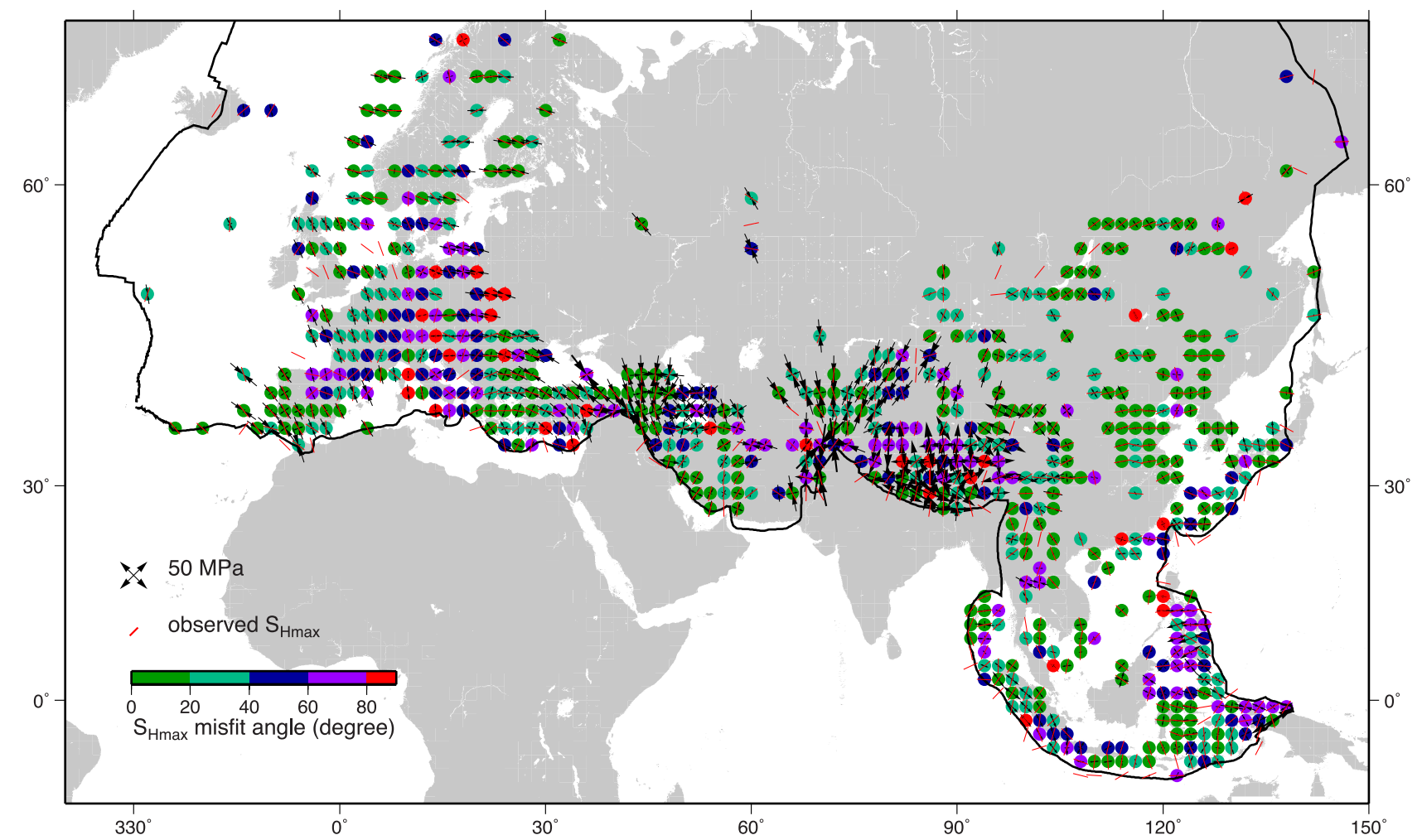

Figure 4. Comparison of stress model results (axes) for force model EUR1best with averaged observations (red stripes). Colours represent local misfit angles. Average model misfit angle is $33^{\circ}$, average data error is $24^{\circ}$.

over compressive collision forces. Eastern Asia is characterized by a strike-slip stress regime resulting from negligible edge forces on the eastern plate boundary. Southeast Asia shows low stress levels with considerable lateral variations in both stress regime and orientations. The absence of significant edge forcing causes GPE forces and mantle tractions to have a dominant imprint here.

The model adequately reproduces the observed large-scale stress directions within WSM data uncertainties for considerable parts of the plate: Scandinavia, Iberia, Aegean, Iran (although quasiuniform compression hampers alignment of $S_{\mathrm{Hmax}}$ directions around the south Caspian Sea), Tien Shan region, Baikal and China (Fig. 4). For model EUR1best, the average misfit angle over the entire domain is $33^{\circ}$ and the average data error is $24^{\circ}$. Four main regions, however, show significant systematic misfits: the central Tibetan Plateau, central Europe and Italy, the western part of the east European platform and the Philippines/Papua. Given the low-stress magnitudes in southeast Asia and the complex internal deformation, we do not consider the misfit in this region as a problem. This is different for the other three regions.

\subsection{Sensitivity of stress field to edge force distribution}

We start the sensitivity analysis of the stress field by focusing on the effect of the distribution of edge forces for a specific combination of mantle flow and LBF model. Although it is not possible to isolate the effect of variations in a single force (because of mechanical balance, changing one force evokes changes in other forces) this approach allows us to identify which forces control the fit with observations. It should give a handle on the extent to which variations in the resistive forces along the Tethys suture zone can be resolved.

As we will demonstrate in Section 5.3, misfit angles for different edge force magnitudes show similar sensitivities to the mantle flow and LBF model. Therefore, Fig. 5 only displays misfit angles for LBF model Lithodens and mantle model ngrand. Here, we present results in terms of plate-wide average misfits as these are quite representative for the behaviour of the models.

Each graph in this figure displays the same models as function of the edge force magnitude. The magnitude range is constrained by torque balance. Models are deemed to be physically realistic if collision forces along the African/Arabian, the Indian and the Australian Plate contact are resistive (positive values). Furthermore, the (vertically integrated) collision force should be strongest on the Indian segment, because it has the largest vertical plate contact area. Models fulfilling these requirements are indicated by filled circles in Fig. 5. Model EUR1best, marked by a red cross, is the physically realistic model that generates the best overall fit with observations.

We find that average misfit angles show a clear dependence on the magnitude of collision forces (Figs $5 \mathrm{a}-\mathrm{c}$ ). Sensitivity to transform fault resistance or forces at roll-back and non-roll-back margins is far less and restricted regionally so that it is not expressed on the plate scale (Figs $5 \mathrm{~d}-\mathrm{f}$, respectively). Force magnitudes on the collisional boundaries with Africa/Arabia, India and Australia strongly correlate: increased forcing on the Indian boundary requires weaker forcing on the other two segments to maintain mechanical equilibrium. Physically realistic models constrain forcing on the Indian boundary to magnitudes between 3.1 and $4.4 \mathrm{TN} \mathrm{m}^{-1}$ (grey band in Fig. 5b).

\subsection{Sensitivity of stress field to uncertainties in mantle tractions and LBFs}

Here, we investigate whether the distribution of mantle tractions and LBFs affects regional stresses. We show results for the three tomographic models used by WR2012 which produce the best fit to 

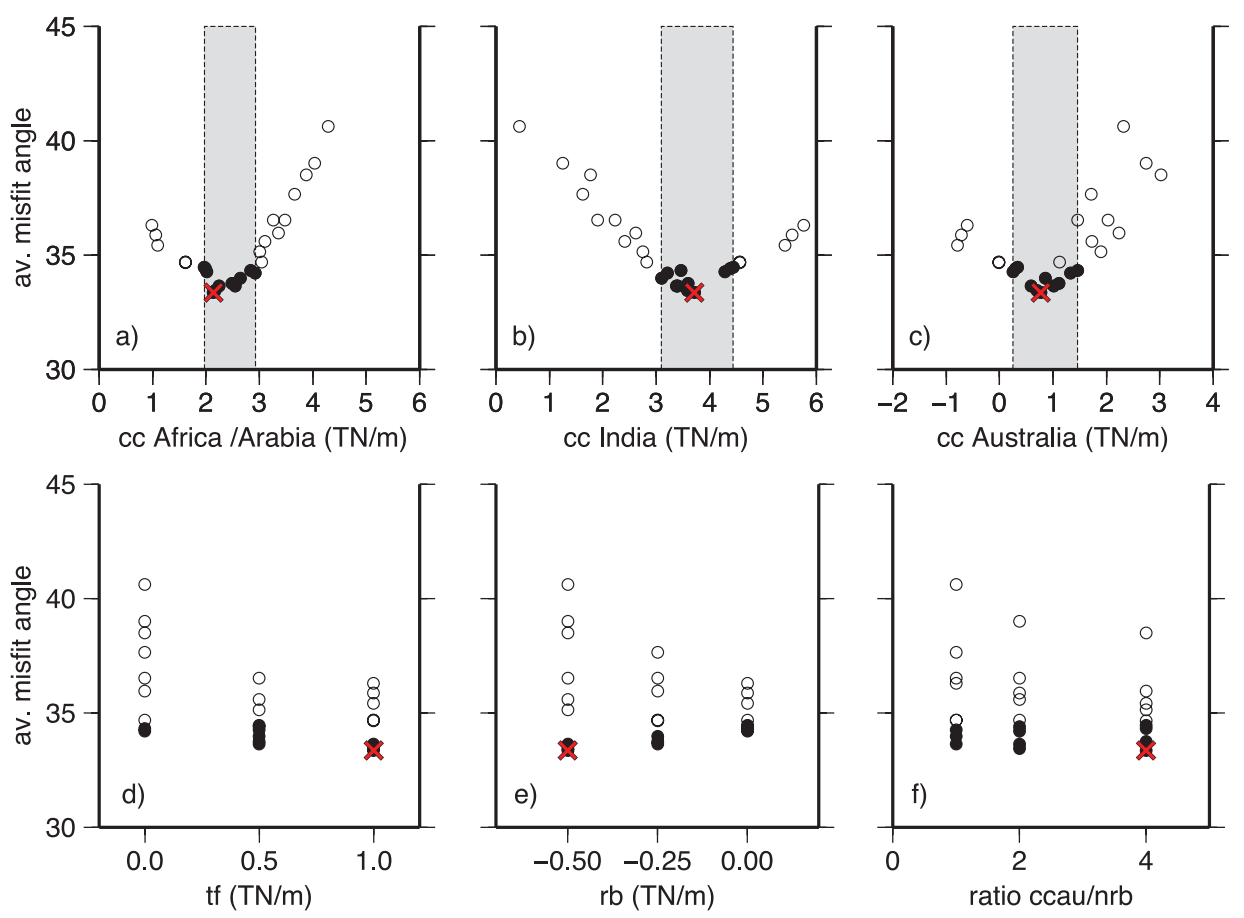

Figure 5. EUR1 models with 'cc' being short for continental collision. Dependence of the misfit in stress directions for the whole Eurasian Plate on the magnitude of (a) collision forces on the African and Arabian plate contact, (b) collision forces on the Indian Plate contact, (c) collision forces on the Australian Plate contact, (d) transform fault resistance (tf), (e) outward pull at roll-back margins (rb) and (f) the ratio of the edge forces at the continental collision and the non-roll-back segments of the Australian boundary (ratio ccau/nrbau). Average data error for the Eurasian Plate is $25^{\circ}$. Results are shown for LBF model Lithodens and mantle tractions based on tomographic model ngrand. Filled circles represent physically realistic force sets (as defined in Section 5.2). These models restrict collision force magnitudes to values enclosed by the grey bands. Model EUR1best is indicated by red cross.

observations [ngrand (Grand 2002), s20rts (Ritsema \& van Heijst 2000) and saw (Megnin \& Romanowicz 2000)] and for the three LBF models presented in Section 2.3. Since the distribution of collision forces has the strongest impact on stress field orientations, we evaluate models as function of the collision force along the India-Eurasia plate boundary (Figs 6 and 7). To assess whether stress orientations are affected regionally, we consider average misfit angles for the subregions Europe, Zagros and the Tibetan Plateau (subregions are indicated by dashed lines in Fig. 1).

Results for the three tomographic models are very similar (Fig. 6). This agrees with Steinberger et al. (2001), who found that modelled stress orientations are relatively insensitive to the choice of global mantle flow model. In all three subregions, a different model seems to consistently somewhat underperform compared to the other two, the largest difference occurring in the Tibetan region. Generally, we find that the indirect effect of mantle tractions on the stress field, caused by edge forces adapting to the zero torque constraint, dominates over the direct effect of their precise distribution. Uncertainty in mantle tractions is therefore unlikely to influence our conclusions regarding the distribution of forces along Eurasia's boundary. Because mantle tractions based on tomographic model ngrand allow for the largest range of physically realistic edge force distributions, we present the rest of our analysis based on this model.

Incorporation of observed crustal thickness variations is essential for the representation of stress orientations in the Zagros, where model Mantle clearly falls short (Fig. 7c). For all regions, stresses are best matched for LBF model Lithodens.

Interestingly, in all cases, physically unrealistic models allowing for higher Indian collision forces generate the best fit to the stress field in the Tibetan region (open circles in the right part of Figs $6 \mathrm{~d}$ and $7 \mathrm{~d}$ ). We conclude that the Lithodens model gives the best fit to the data and that the stress field is insensitive to the mantle convection model.

\subsection{Overall findings of sensitivity analysis}

The large-scale Eurasian stress field is predominantly sensitive to the magnitude of collision forces, although it is somewhat affected by alternative choices of mantle tractions and LBFs. We tested this conclusion to be independent of the averaging distance of the data. From Figs 6(d) and 7(d), we conclude that, independent of the LBF and mantle flow model, stress observations in Tibet are best matched by physically unrealistic models (open symbols) with Indian collision forces exceeding about $5 \mathrm{TN} \mathrm{m}^{-1}$. These magnitudes are required to compensate for collapse forces (LBFs) of the Tibetan Plateau. Within the restrictions of the EUR1-class distribution of edge forces, such magnitudes on the Indian Plate contact can only be counterbalanced by unrealistic outward forcing on other collisional boundaries. We therefore proceed to refine the edge force distribution.

\section{MODEL REFINEMENT OF EDGE FORCE DISTRIBUTION}

\subsection{Refinement of edge force distribution}

Because the total edge force torque is constrained through mechanical equilibrium, larger collision forces on the Indian contact require compensating forces elsewhere on the plate boundary. We consider three variations on the EUR1 models distribution of edge forces adopted thus far, to form a model class we will refer to as EUR2: 


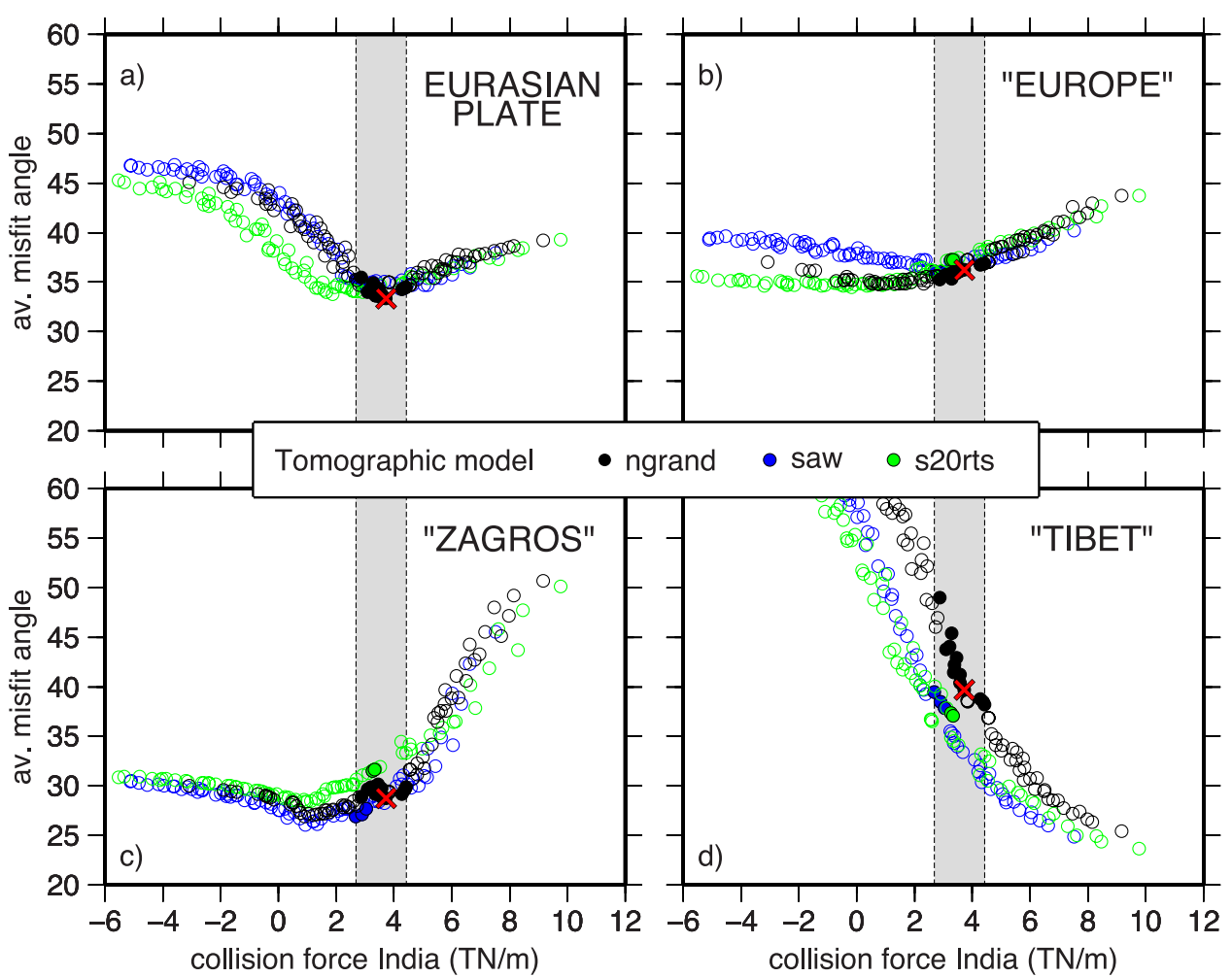

Figure 6. EUR1 models. Dependence of average misfit angle on mantle flow model (see text for tomographic model references) as function of the magnitude of collision forces on the Indian Plate contact. Results are given for (a) the whole Eurasian Plate (average data error $25^{\circ}$ ), (b) Europe subregion ( $35^{\circ}$ data error), (c) Zagros subregion ( $24^{\circ}$ data error) and (d) Tibet subregion (24 data error). Grey band indicates magnitude range for physically realistic models (models represented by closed symbols). Model EUR1best is indicated by the red cross. LBFs are from model Lithodens.

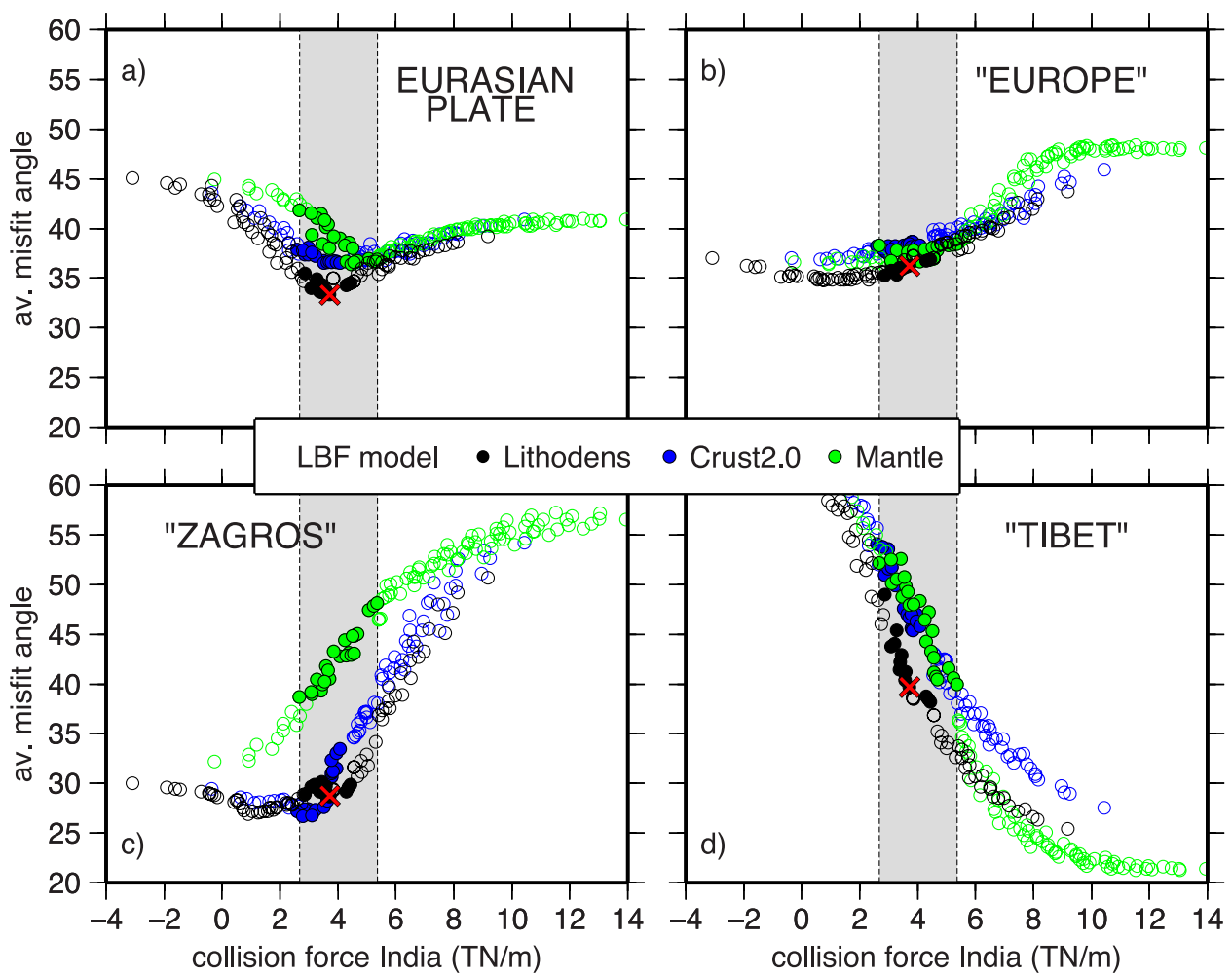

Figure 7. EUR1 models. Dependence of average misfit angle on LBF model as function of the magnitude of collision forces on the Indian Plate contact. Results are given for (a) the whole Eurasian Plate (average data error $25^{\circ}$ ), (b) Europe subregion ( $35^{\circ}$ data error), (c) Zagros subregion (24 data error) and (d) Tibet subregion ( $24^{\circ}$ data error). Grey band indicates magnitude range for physically realistic models (models represented by closed circles). Model EUR1best is indicated by red cross. Mantle tractions are derived from tomographic model ngrand with viscosity profile (Mitrovica \& Forte 2004) and $v-\rho$ scaling magnitude 0.18 . 
(1) A considerable uncertainty in the assessment of edge forces lies in the treatment of the unknown continental boundary with the North American Plate. Thus far, prompted by the lack of seismic activity, we let this boundary free. Some level of forcing, however, may be present without finding an expression in the old and strong lithosphere that characterises the region surrounding this boundary. We consider forcing on this boundary in the direction of relative motion. Due to the vicinity of the Euler pole (Sella et al. 2002), forces are directed in a fan-like pattern, outwards on its northeastern part and inwards on its southwestern part (Hindle et al. 2006).

(2) India's collision with Eurasia is highly oblique on the Pakistan and Birma segments of the boundary between the two plates (Fig. 1). Transmission of stress on what can be considered a continental transform boundary is likely reduced with respect to the central part of the plate contact. We therefore separate the oblique segments of the Indian boundary from the central part and independently solve for the magnitude of forcing.

(3) We allow different force magnitudes on the African and the Arabian collisional plate boundary segments.

We find that the edge force distributions of the EUR2 models slightly improves the relation between plate-wide averaged misfit angle and the magnitude of Indian collision forces when the latter exceed $4 \mathrm{TN} \mathrm{m}^{-1}$.

In the Tibet region, the stress field is considerably better matched for the higher collision forces as allowed by the EUR2-class of models (Fig. 8d). A consequence of torque balance is that forces on the African and Arabian segments are lower for force models with higher Indian collision. Fig. 8(b) shows that the misfit deteriorates marginally in Europe. Stresses on the Zagros region are insensitive to variations in collision forces unless Indian collision forces exceed $10 \mathrm{TN} \mathrm{m}^{-1}$ (Fig. 8c). Increased collision forcing on the Arabian boundary relative to that of Africa improves the stress match in Tibet by allowing for higher collision forces on the Indian Plate contact but results in higher misfits in Zagros (blue versus green circles in Figs 8c and d).

A clear division between force models that acceptably match overall stress observation in Eurasia and models that do not is not straightforward because of differential behaviour of the various regions. As a result, we cannot constrain the ratio of collision forces on the African segment and the Arabian boundary segment. To constrain the magnitude of India-Eurasia collision forces, we focus on the Tibetan region because (1) stress observations show the strongest sensitivity to the range of physically acceptable force models, (2) stress observations are relatively consistent (which is not the case in Europe) and (3) modelled stresses have a clear $S_{\mathrm{Hmax}}$ (which is not the case for the uniform compression modelled in Zagros). Indian collision forces between 7.0 and $10.5 \mathrm{TN} \mathrm{m}^{-1}$ result in misfits in the Tibetan region of less then $30^{\circ}$ (average data error $24^{\circ}$ ) while being part of physically realistic models for the entire Eurasian Plate (Fig. 8d, range indicated by grey band). These models generate misfits no more than 20 per cent higher than the best performing model and are all deemed acceptable. The magnitude range found for the Indian collision implies African collision forces between 1.0 and $2.5 \mathrm{TN} \mathrm{m}^{-1}$, Arabian collision forces between 1.3 and $2.7 \mathrm{TN} \mathrm{m}^{-1}$ and low forces on the Australian collision $\left(0-1.3 \mathrm{TN} \mathrm{m}^{-1}\right)$. Results for the magnitude range of collisional forces along Eurasia's southern margin are summarized in Table A1.

Fig. 9 shows the edge force distribution and resulting stress field for model EUR2best, which shows the lowest plate-wide misfit.

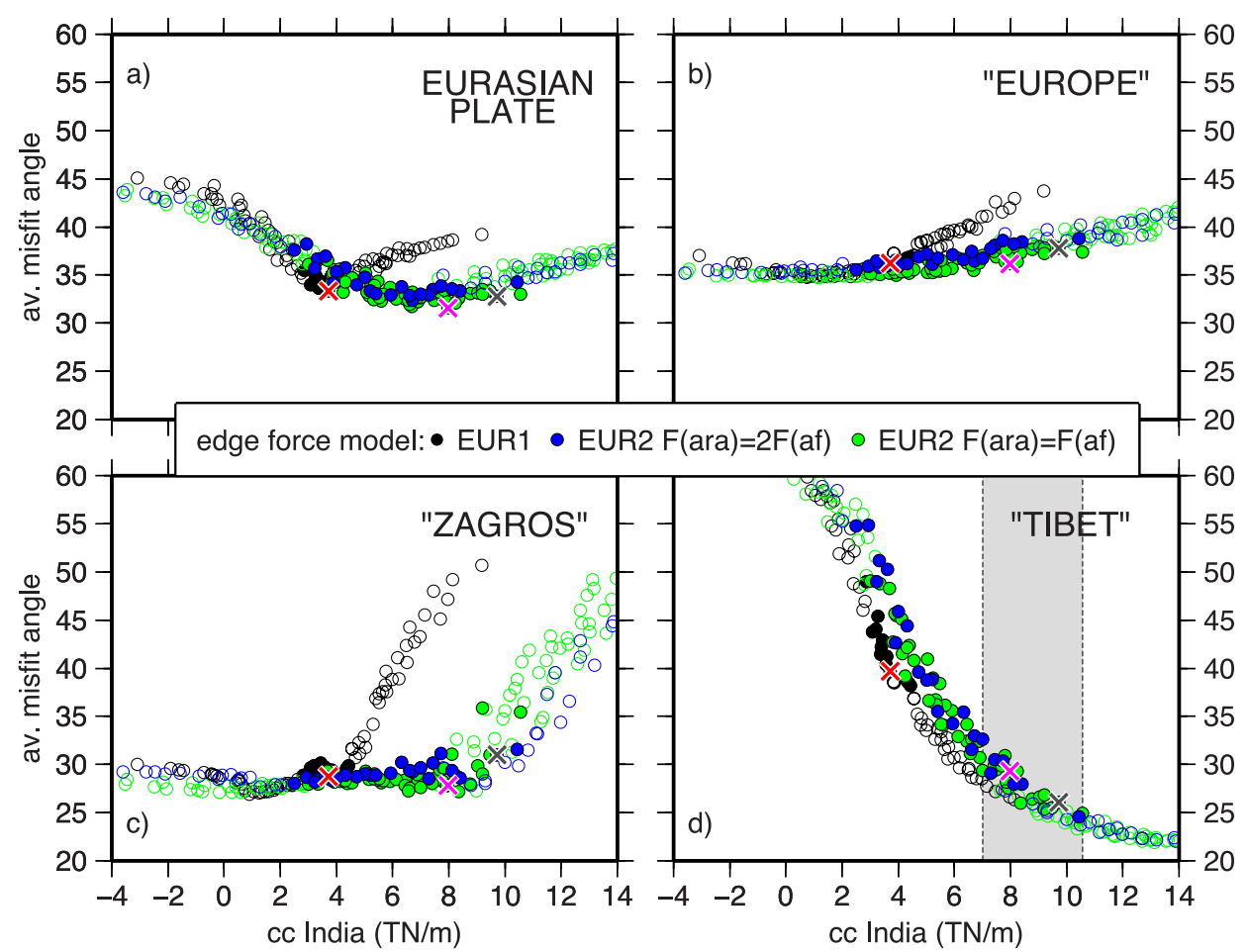

Figure 8. Average misfit angle as function of the magnitude of collision forces on the Indian Plate contact for EUR1 models (black), EUR2 models with Arabian collision twice as strong as African collision (dark blue) and models based on EUR2 but with equal collision forcing along the Africa and Arabia boundary (green). The best-fitting models of each category are indicated by the red cross (EUR1best), pink cross and grey cross (EUR2best). Results are given for (a) the whole Eurasian Plate (average data error $25^{\circ}$ ), (b) Europe subregion ( $35^{\circ}$ data error), (c) Zagros subregion ( $24^{\circ}$ data error) and (d) Tibet subregion ( $24^{\circ}$ data error). Grey band indicates magnitude range for physically realistic EUR2 models (models represented by closed circles) with misfit angles $<30^{\circ}$ in the Tibet subregion. Results are shown for LBF model Lithodens and mantle tractions based on tomographic model ngrand. 


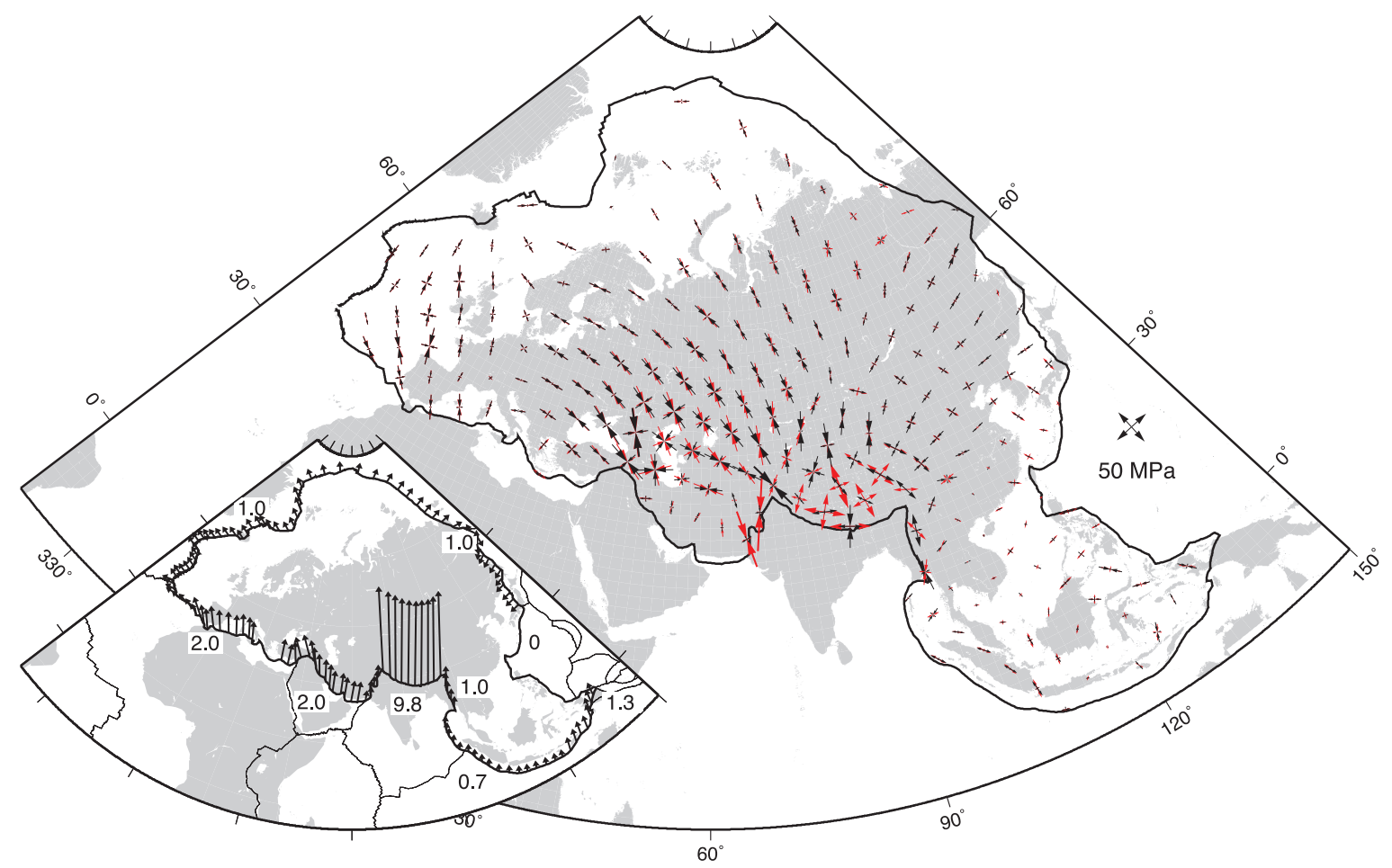

Figure 9. Stress field for force model EUR2best (black axes) compared to model EUR1best (red axes). Corresponding EUR2best edge forces are displayed in the inset; numbers are average magnitudes in $\mathrm{TN} \mathrm{m}^{-1}$.

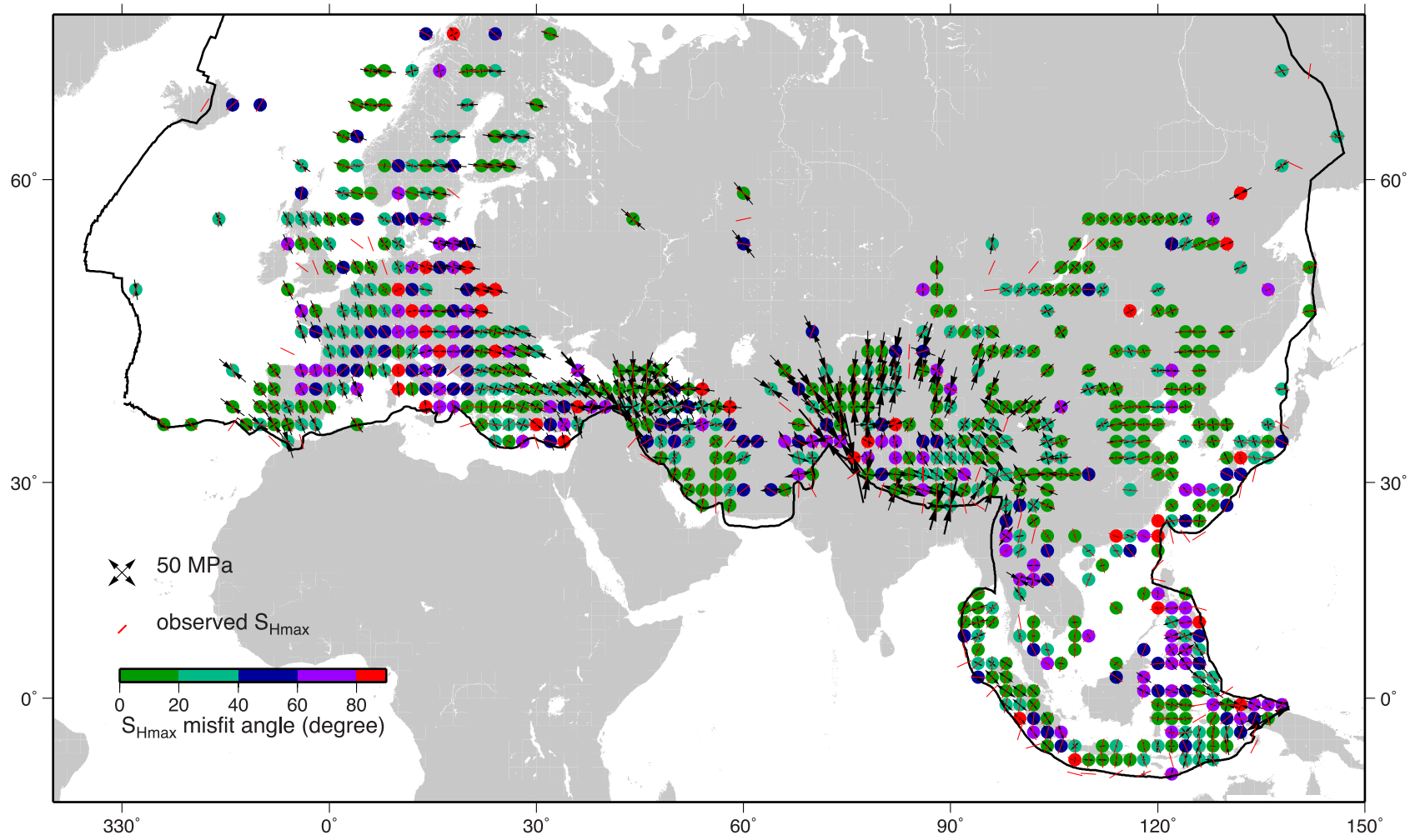

Figure 10. Comparison of stress results (stress axes) for force model EUR2best with observations (red stripes). Colours represent local misfit angles. Average misfit angle is $32^{\circ}$, average data error is $24^{\circ}$.

Indian collision forces are twice as strong as in model EUR1best, improving the data fit for the Tibet subregions by $9^{\circ}$. This is significant relative to the $30^{\circ}$ range spanned by all EUR2 models. Stress amplitudes in the northeastern part of the plate are slightly increased due to the combination of strong collision forces and forcing on the North American boundary. Stress orientations in this part of the plate remain unchanged and fit observations well (Fig. 10). Relative to EUR1best, stresses in Europe are slightly rotated due to the 


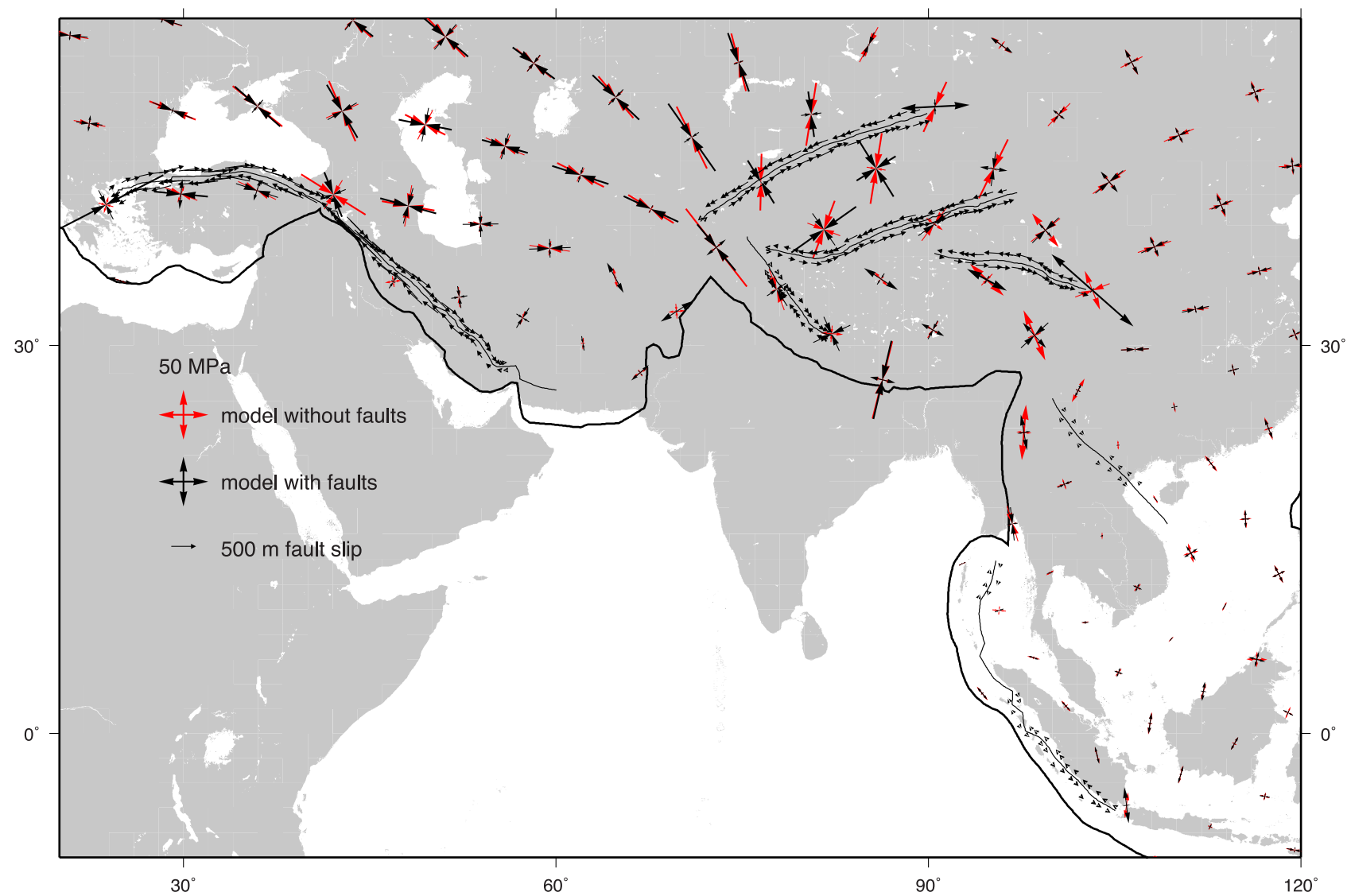

Figure 11. Effect of faults on modelled stress field. Stress field results for same force model with (black axes) and without (red axes) faults. Model slip directions are indicated by black arrows.

different forcing on the African and Arabian collision zones, but the match with observations remains poor at $36^{\circ}$. However, data error is large here $\left(35^{\circ}\right)$ largely due to significant spread in stress directions in central and southern Europe and this is thus a less than ideal region to test our model results. This might also be the reason why, as mentioned earlier, relative force magnitudes between the African and Arabian collision could not be well resolved.

Although the plate-wide $S_{\mathrm{Hmax}}$ orientation misfit is only slightly reduced compared to model EUR1best and remains considerable at $32^{\circ}$ (average data error $25^{\circ}$ ), refinement of the edge force distribution results in a considerably better representation of stresses in the Tibetan Plateau. As this is a region with above average resolution of stress observations, we value this regional improvement and give preference of the EUR2 models over EUR1.

\subsection{Effect of internal faults}

We investigate how model stresses are affected by incorporating major strike-slip fault or shear zones in the EUR2best model. Active fault/shear zones are identified on the basis of seismic activity and GPS data from the model of Kreemer et al. (2003). We include eight discontinuities in our model; North Anatolian, mainrecent-Zagros, Karakorum, Altyn Tagh, Kunlun, Red River and great-Sumatra faults, and the Tien Shan shear zone. Each feature is approximated by a single fault in our model (black lines inside our model plate in Fig. 1). We use a slippery node technique (Melosh \& Williams 1989) that allows for fault parallel slip. Because we model the long time averaged stress field, we do not consider earthquake cycles and do not apply friction on the faults. Their finite length and local changes in orientation do, however, introduce mechanical resistance.

Fig. 11 shows the stress field for the EUR2best model with and without faults (Fig. 9). As expected, $S_{\mathrm{H} \max }$ orientations rotate towards strike normal directions in the vicinity of a fault. However, the lateral extent of stress field rotations is small compared to the scale of our domain and plate-wide averaged misfit angles are hardly affected.

This indicates that our results regarding the distribution of forces acting on the Eurasian Plate are not likely to be affected by the isotropic rheology used in this study.

An interesting result is the predicted sense of shear on faults, which is an additional test of the force field. We find that observed slip directions are generally well reproduced (right lateral: North Anatolian, main-recent-Zagros, Karakoram, Red-River and greatSumatra faults, left lateral: Althyn Thag and Kunlun faults, Tien Shan shear zone). We do not resolve slip on the great-Sumatran and Red-River faults, probably due to the negligible edge forcing in southeast Asia. Models with larger resistive forces on the Sunda (Java/Sumatra) subduction zone (around $2 \mathrm{TN} \mathrm{m}^{-1}$ ) show increased right-lateral slip over the entire length of these two faults, suggesting that actual forcing on the boundary in southeast Asia may be somewhat higher than inferred from our models.

\section{CORRELATION OF COLLISION FORCES WITH PLATEAU HEIGHT}

In this section, we assess whether the classical view that the mean elevation of an orogenic plateau can be taken as a measure of the 


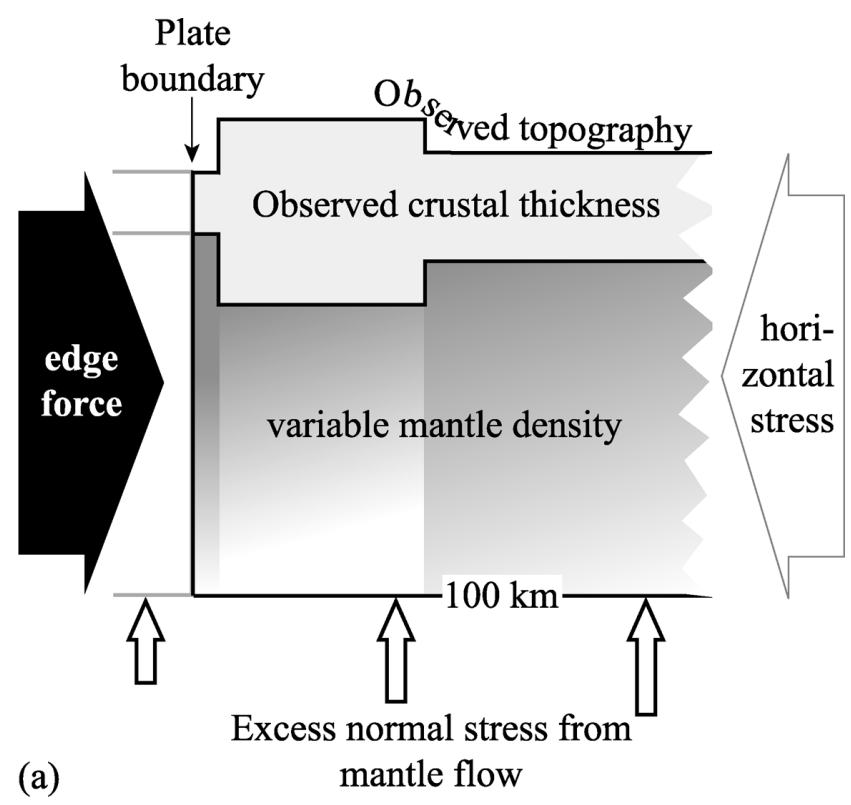

Force per unit plate boundary length $(\mathrm{TN} / \mathrm{m})$

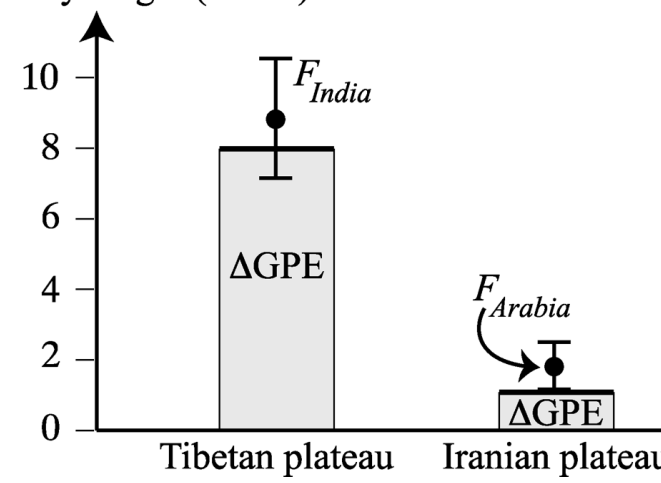

(b)

\section{Tibetan plateau Iranian plateau}

Figure 12. (a) Schematic cross-section through a lithospheric plate boundary region with topography, for example, a south (left)-north (right) section from northern India into the Tibetan Plateau. The horizontal black arrow represents the net edge force by the lithosphere to the left of the plate boundary on the lithosphere to the right. The horizontal white arrow represents the net horizontal force from intraplate stresses in the lithosphere on the right. (b) Magnitude of $\triangle \mathrm{GPE}$ across the plate boundary for the Tibet and Iranian plateaus. $F_{\text {India }}$ and $F_{\text {Arabia }}$ represent the collisional edge force at these plate boundaries.

magnitude of the collision-related compressive forces involved (Molnar \& Lyon-Caen 1988) is valid for the Iranian and Tibetan plateaus. We do this by comparing our estimates for the magnitude of collision forces on the relevant plate boundary with the GPE contrast of the plateaus.

Fig. 12(a) shows a cross-section of the lithosphere, schematically displaying the dynamics involved. The plate boundary separates an incoming plate on the left from the lithosphere on the right, on which we focus. The plate continues beyond the right boundary, where other forces act. The sum of these forces is equal to the integral of horizontal traction components ('horizontal stress') on the vertical plane on the right side of the figure. Collision leads to crustal thickening, topography and other lateral variations in density, resulting in a contrast in GPE across the plate boundary. Convective mantle flow also contributes to the GPE of both plates. Ridge push is the best example of horizontal gradients in GPE bringing about a significant horizontal force, and similar forces may thus be expected here. Mechanical balance of the plate requires torques deriving from collision forces to be counteracted by torques from other forces. In the 2-D flat-Earth world of Fig. 12(a), horizontal force balance is equivalent to the edge force on the left being equal to the force on the right plus the net GPE related force. From a physics point of view, the edge force (i.e. regional collision force) thus does not need to be correlated with a regional GPE gradient.

For the two plateaus considered here, we find that the average GPE contrast of the Tibetan Plateau relative to the India subcontinent is about $8 \mathrm{TN} \mathrm{m}^{-1}$ (Fig. 13), whereas the average GPE contrast of the Iranian Plateau relative to the Arabia Plate is about $1 \mathrm{TN} \mathrm{m}^{-1}$. Grey columns in Fig. 12(b) display these estimates. Also shown in Fig. 12(b) are our edge forces estimates $F_{\text {India }}$ and $F_{\text {Arabia }}$. The India edge force is equal to (within uncertainties) the GPE contrast, that is, the Tibetan Plateau is in topographic balance. The edge force by Arabia is only incrementally higher than the GPE contrast of the Iranian Plateau. However, in view of the uncertainties in $\triangle \mathrm{GPE}$ (WR2012), we do not consider this difference to be significant. The difference between the India and Arabia collision forces $\left(7 \mathrm{TN} \mathrm{m}^{-1}\right)$ matches the difference in $\triangle$ GPE between the two plateaus. We conclude that the topography of both the Tibetan and the Iranian plateaus is in balance with the collision force. We note, however, that in both regions the median value of the edge force is slightly higher than the GPE excess, hinting at the possibility that the topography is lagging somewhat in its build-up.

\section{DISCUSSION}

\subsection{Edge force magnitudes}

Our analysis suggests strong lateral variations in forcing magnitude on Eurasia's southern collisional boundary (Table A1). Stronger forcing on the Indian Plate contact is expected as a result of an increase in both the thickness of the collisional boundary and the speed of the approaching plate. Our result for the collision force magnitude on the Indian boundary is higher than suggested by Copley et al. (2010) based on a comparison of the dynamics of the Indian Plate before and after collision with Eurasia $\left(5-6 \mathrm{TN} \mathrm{m}^{-1}\right)$. The discrepancy may be explained by slab pull acting on the Indian Plate, and not on Eurasia. At the plate contact, the net force acting on the India Plate results from an approximately southward-directed collision force and a roughly northwards directed slab pull. As a consequence, the magnitude of the net force on the Indian Plate is smaller than the collision force on Eurasia.

We systematically find that force models that best reproduce the stress field on the plate scale have low edge forces in southeast Asia. Although higher forcing slightly improves the regional match with observations, this affects the remainder of the edge force distribution and deteriorates the match with observations elsewhere. The small contribution of edge forces in southeast Asia to the torque balance of Eurasia suggest low mechanical coupling to the rest of the plate.

Torque balance solutions for the magnitudes of edge forces depend on the net torque generated by LBFs and mantle shear stresses and are thus sensitive to uncertainties herein. We assess the uncertainty in LBFs and mantle tractions by considering various models and find that they result in edge force solutions with similar characteristics. The physical models for LBFs and mantle tractions can be further refined to incorporate lateral variations in lithospheric thickness and mantle viscosity. As outlined in WR2012, these model refinements probably affect model forces (and thus stresses) regionally but are not expected to considerably influence plate-scale 


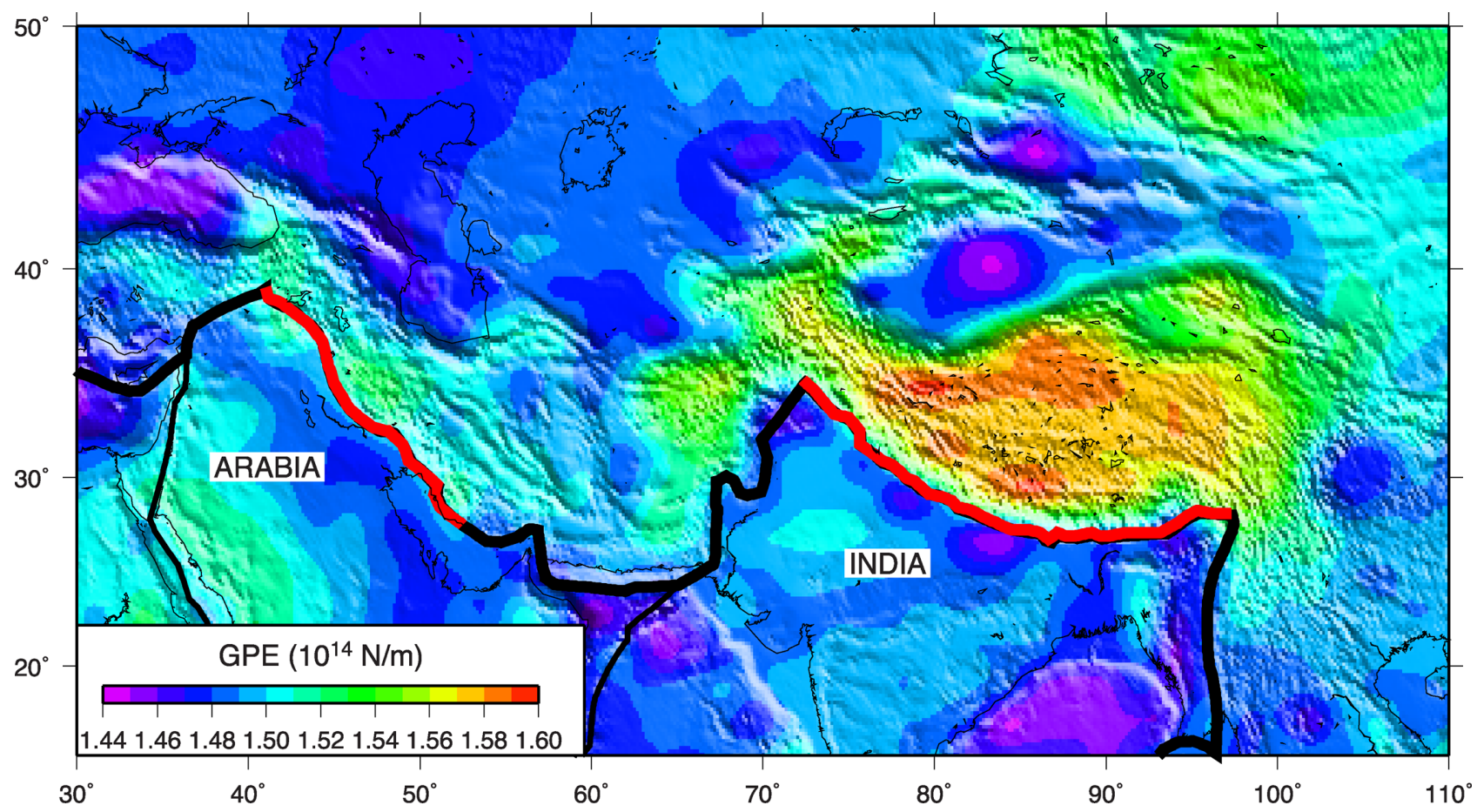

Figure 13. GPE distribution of the Tibetan and Iranian plateaus and surrounding regions based on density structure model Lithodens (see Section 2.3). Thick black lines represent plate boundaries; red lines indicate the sections of the Arabian and Indian plate margins against which the excess GPE of the Iranian and Tibetan plateaus are determined, respectively.

quantities (Becker 2006). Therefore, they are unlikely to affect our conclusions regarding the distribution of edge forces on Eurasia's boundary.

\section{CONCLUSIONS}

We build on the results of Warners-Ruckstuhl et al. (2012), who combine edge forces with physical models for LBFs and tractions from global mantle flow models to identify sets of forces that (i) are in mechanical equilibrium and (ii) drive the Eurasian Plate in the observed direction of absolute motion. Here, we use the observed intraplate stress field to put further constraints on the distribution of these forces with a special interest in the collision forces along the Neo-Tethys suture zone. We conclude that:

(i) Collision forces along the southern plate boundary govern the fit to the observed large-scale Eurasian stress field.

(ii) Stress observations require collision forces on the IndiaEurasia boundary of $7.0-10.5 \mathrm{TN} \mathrm{m}^{-1}$. Implication of mechanical equilibrium is that forces on the African, Arabian and Australian plate contacts amount to $1.0-2.5,1.3-2.7$ and $0-1.3 \mathrm{TN} \mathrm{m}^{-1}$, respectively.

(iii) The stress field is sensitive to the lithospheric density structure and to tractions resulting from lithosphere-mantle coupling, albeit less strongly so than to the magnitude of collision forces.

(iv) For both the Tibetan and the Iranian plateaus, the horizontal force derived from the excess GPE (collapse force) is in equilibrium with the collision force.

\section{ACKNOWLEDGEMENTS}

We thank Lucy flesh and Greg Houseman for careful reviews of an earlier version of this manuscript as part of the evaluation of KWR's thesis and Douwe van Hinsbergen for comments that helped to improve the manuscript. Editor Saskia Goes and an anonymous reviewer provided valuable comments that helped to improve the manuscript structure and our discussion of the model misfits. Figures were produced with the GMT software by Wessel \& Smith (1998). Work supported in part by the Netherlands Organisation for Scientific Research [NWO, Earth and Life Sciences (ALW)], in the context of the EUROMARGINS EUROCORES Programme of the European Science Foundation, project 01-LEC-EMA22F WESTMED

\section{REFER E N CES}

Agard, P., Omrani, J., Jolivet, L. \& Mouthereau, F., 2005. Convergence history across Zagros (Iran): constraints from collisional and earlier deformation, Int. J. Earth Sci., 94(3), 401-419.

Aitchison, J.C., Ali, J.R. \& Davis, A.M., 2007. When and where did India and Asia collide? J. geophys. Res., 112(B5), B05423, doi:10.1029/2006JB004706.

Amante, C. \& Eakins, B.W., 2009. ETOPO1 1 arc-minute global relief model: procedures, data sources and analysis, NOAA Technical Memorandum NESDIS NGDC-24, p. 19.

Artyushkov, E.V., 1973. Stresses in the lithosphere caused by crustal thickness inhomogeneities, J. geophys. Res., 78, 7675-7708.

Bassin, C., Laske, G. \& Masters, G., 2000. The current limits of resolution for surface wave tomography in North America, EOS, Trans. Am. geophys. Un., 81, F897.

Becker, T.W., 2006. On the effect of temperature and strain-rate dependent viscosity on global mantle flow, net rotation and plate-driving forces, Geophys. J. Int., 167, 943-957.

Becker, T.W. \& O’Connell, R.J., 2001. Predicting plate velocities with mantle circulation models, Geochem. Geophys. Geosyst., 2 , doi:10.1029/2001GC000171

Becker, T.W., Conrad, C., Lithgow-Bertelloni, C., O’Connell, R., O’Neill, C., Richards, M., Steinberger, B. \& Zhong, S., 2006. Global spectral flow code development and benchmark plan. Available at: http://geosys.usc.edu/projects/seatree, Last accessed April 2011. 
Bird, P., 2003. An updated digital model of plate boundaries, Geochem. Geophys. Geosyst., 4, doi:10.1029/2001GC000252.

Bird, P., Liu, Z. \& Rucker, W.K., 2008. Stresses that drive the plates from below: definitions, computational path, model optimization and error analysis, J. geophys. Res., 113, doi:10.1029/2007JB005460.

Carminati, E., Wortel, M.J.R., Spakman, W. \& Sabadini, R., 1998. The role of slab detachment processes in the opening of the western-central Mediterranean basins: some geological and geophysical evidence, Earth planet. Sci. Lett., 160(3-4), 651-665.

Chapman, M.E. \& Solomon, S.C., 1976. North American-Eurasian boundary in north east Asia, J. geophys. Res., 81, 921-930.

Chapple, W.M. \& Tullis, T.E., 1977. Evaluation of the forces that drive the plates, J. geophys. Res., 82, 1967-1984.

Copley, A., Avouac, J.P. \& Royer, J.Y., 2010. India-Asia collision and the Cenozoic slowdown of the Indian plate: implications for the forces driving plate motions, J. geophys. Res., 115, doi:10.1029/2009JB006634.

Davis, D., Suppe, J. \& Dahlen, F.A., 1983. Mechanics of fold-andthrust belts and accretionary wedges, J. geophys. Res., 88(B2), 11531172.

DeMets, C., Gordon, R.G., Argus, D.F. \& Stein, S., 1994. Effect of recent revisions to the geomagnetic reversal time scale on estimates of current plate motion, Geophys. Res. Lett., 21, 2191-2194.

Dercourt, J., Ricou, L.E. \& Vrielynck, 1993. Atlas Téthys, Palaeoenvironmental Maps, Elsevier, New York.

England, P. \& Houseman, G., 1989. Extension during continental convergence, with application to the Tibetan plateau, J. geophys. Res., 94, 17 561-17 579.

Fleitout, L. \& Froidevaux, C., 1982. Tectonics and topography for a lithosphere containing density hertrogeneities, Tectonics, 1, 21-56.

Flesch, L.M., Haines, A.J. \& Holt, W.E., 2001. Dynamics of the IndiaEurasia collision zone, J. geophys. Res., 106, 16 435-16 460.

Forsyth, D.W. \& Uyeda, S., 1975. On the relative importance of the driving forces of plate motion, Geophys. J. R. astr. Soc., 43, 163-200.

Gölke, M. \& Coblentz, D.D., 1996. Origins of the European stress field, Tectonophysics, 266, 11-24.

Govers, R. \& Meijer, P.T., 2001. On the dynamics of the Juan de Fuca plate, Earth planet. Sci. Lett., 189, 115-131.

Grand, S.P., 2002. Mantle shear wave tomography and the fate of subducted slabs, Phil. Trans. R. Soc. London, 360, 2475-2491.

Grünthal, G. \& Stromeyer, D., 1992. The recent crustal stress field in central Europe: trajectories and finite element modeling, J. geophys. Res., 97, $11805-11820$

Hafkenscheid, E., Wortel, M.J.R. \& Spakman, W., 2006. Subduction history of the Tethyan region derived from seismic tomography and tectonic reconstructions, J. geophys. Res., 111(B8), B08401, doi:10.1029/2005JB003791

Hager, B.H. \& O'Connell, R.J., 1981. A simple global model of plate dynamics and mantle convection, J. geophys. Res., 86, 4843-4867.

Hager, B.H., Clayton, R.W., Richards, M.A., Comer, R.P. \& Dziewonski, A.M., 1985. Lower mantle heterogeneity, dynamic topography and the geoid, Nature, 113, 541-545.

Heidbach, O., Tingay, M., Barth, A., Reinecker, J., Kurfeß, D. \& Müller, B., 2008. The world stress map database release 2008 , doi:10.1594/GFZ.WSM.Rel2008.

Hieronymus, C.F., Goes, S., Sargent, M. \& Morra, G., 2008. A dynamical model for generating Eurasian lithospheric stress and strain rate fields: effect of rheology and cratons, J. geophys. Res., 113, B07404, doi:10.1029/2007JB004953

Hindle, D., Fujita, K. \& Mackey, K., 2006. Current deformation rates and extrusion of the northwestern Okhotsk plate, northeast Russia, Geophys. Res. Lett., 33(2306), 1-4.

Hinsbergen, D., Lippert, P., Dupont-Nivet, G., McQuarrie, N., Doubrovine, P., Spakman, W. \& Torsvik, T., 2012. Greater India Basin hypothesis and a two-stage Cenozoic collision between India and Asia, Proc. Natl. Acad. Sci. USA, 109, 7659-7664.

Iaffaldano, G. \& Bunge, H.P., 2009. Relating rapid plate-motion variations to plate-boundary forces in global coupled models of the mantle/lithosphere system: effects of topography and friction, Tectonophysics, 474, 393-404.
Kreemer, C., Holt, W.E. \& Haines, A.J., 2003. An integrated global model of present-day plate motions and plate boundary deformation, Geophys. J. Int., 154, 8-34.

Lithgow-Bertelloni, C. \& Guynn, J.H., 2004. Origin of the lithospheric stress field, J. geophys. Res., 109, doi:10.1029/2003JB002467.

Lithgow-Bertelloni, C. \& Silver, P.G., 1998. Dynamic topography, plate driving forces and the African superswell, Nature, 395, 269-272.

Mardia, K.V., 1972. Statistics of Directional Data, Academic Press, London.

Megnin, C. \& Romanowicz, B., 2000. The shear velocity structure of the mantle from the inversion of body, surface and higher modes waveforms, Geophys. J. Int., 143, 709-728.

Meijer, P.T. \& Wortel, M.J.R., 1992. The dynamics of motion of the South American plate, J. geophys. Res., 97, 11 915-11931.

Melosh, H.J. \& Williams, C.A., 1989. Mechanics of graben formation in crustal rocks: a finite element analysis, J. geophys. Res., 94(B10), 13 96113973.

Milner, K., Becker, T.W., Boschi, L., Sain, J., Schorlemmer, D. \& Waterhouse, H., 2009. The solid Earth research and teaching environment: a new software framework to share research tools in the classroom and across disciplines, EOS, Trans. Am. geophys. Un., 90, 12.

Mitrovica, J.X. \& Forte, A.M., 2004. A new inference of mantle viscosity based upon joint inversion of convection and glacial isostatic adjustment data, Earth planet. Sci. Lett., 225, 177-189.

Molnar, P. \& Lyon-Caen, H., 1988. Some simple physical aspects of the support, structure, and evolution of mountain belts, Spec. Pap. Geol. Soc. Am., 218, 179-207.

Molnar, P. \& Tapponnier, P., 1975. Cenozoic tectonics of Asia: effects of a continental collision, Science, 189(4201), 419-426.

Mouthereau, F., Lacombe, O. \& Vergés, J., 2012. Building the Zagros collisional orogen: timing, strain distribution and the dynamics of Arabia/Eurasia plate convergence, Tectonophysics, 532-535(C), 27-60.

Özeren, M.S. \& Holt, W.E., 2010. The dynamics of the eastern Mediterranean and eastern Turkey, Geophys. J. Int., 183(3), 1165-1184.

Rey, P.F. \& Houseman, G., 2006. Lithospheric scale gravitational flow: the impact of body forces on orogenic processes from Archaean to Phanerozoic, Geol. Soc. Lond. Spec. Publ., 253(1), 153-167.

Ricard, Y. \& Vigny, C., 1989. Mantle dynamics with induced plate tectonics, J. geophys. Res., 94(B12), 17 543-17 559.

Ritsema, J. \& van Heijst, H.J., 2000. Seismic imaging of structural heterogeneity in Earth's mantle: evidence for large-scale mantle flow, Sci. Prog., 83, 243-259.

Sella, G., Dixon, T. \& Mao, A., 2002. REVEL: a model for recent plate velocities from space geodesy, J. geophys. Res., 107(B4), 2081, doi:10.1029/2000JB000033.

Şengör, A.M.C. \& Natal'in, B.A., 1996. Paleotectonics of Asia: Fragments of a synthesis, in The Tectonic Evolution of Asia, pp. 486-640, eds Yin, A. \& Harrison, T.M., Cambridge University Press, New York.

Simmons, N.A., Forte, A.M., Boschi, L. \& Grand, S.P., 2010. Gypsum: a joint tomographic model of mantle density and seismic wave speeds, $J$. geophys. Res., 115, B12310, doi:10.1029/2010JB007631.

Spakman, W. \& Hall, R., 2010. Surface deformation and slab-mantle interaction during Banda arc subduction rollback, Nature Geosci., 3(8), 562-566.

Stadler, G., Gurnis, M., Burstedde, C., Wilcox, L.C., Alisic, L. \& Ghattas, O., 2010. The dynamics of plate tectonics and mantle flow: from local to global scales, Science, 329(5995), 1033-1038.

Stampfli, G. \& Borel, G.D., 2002. A plate tectonic model for the Paleozoic and Mesozoic constrained by dynamic plate boundaries and restored synthetic oceanic isochrons, Earth planet. Sci. Lett., 196, 17-33.

Stampfli, G.M. \& Borel, G.D., 2004. The TRANSMED transects in space and time: constraints on the paleotectonic evolution of the Mediterranean domain, in The TRANSMED Atlas: The Mediterranean Region from Crust to Mantle, pp. 53-80, eds Cavazza, W., Roure, F.M., Spakman, W., Stampfli, G.M. \& Ziegler, P.A., Springer, Berlin, Heidelberg, New York.

Steinberger, B., 2000. Slabs in the lower mantle - results of dynamic modelling compared with tomographic images and the geoid, Phys. Earth planet. Int., 118, 241-257. 
Steinberger, B., Schmeling, H. \& Marquart, G., 2001. Large-scale stress field and topography induced by global mantle circulation, Earth planet. Sci. Lett., 186, 75-91.

Vergnolle, J., Calais, E. \& Dong, L., 2007. Dynamics of continental deformation in Asia, J. geophys. Res., 112, B11403, doi:10.1029/2006JB004807.

Warners-Ruckstuhl, K.N., Meijer, P.T., Govers, R. \& Wortel, M.J.R., 2010. A lithosphere-dynamics constraint on mantle flow: analysis of the Eurasian plate, Geophys. Res. Lett., 37, doi:10.1029/2010GL044431.

Warners-Ruckstuhl, K.N., Govers, R. \& Wortel, R., 2012. Lithospheremantle coupling and the dynamics of the Eurasian plate, Geophys. J. Int., 189, doi:10.1111/j.1365-246X.2012.05427.x.

Wessel, P. \& Smith, W.H.F., 1998. New, improved version of Generic Mapping Tools released, EOS, Trans. Am. geophys. Un., 79, 579.

Wortel, M.J.R., Remkes, M.J.N., Govers, R., Cloetingh, S.A.P.L. \& Meijer, P.T., 1991. Dynamics of the lithosphere and the intraplate stress field, Phil. Trans. R. Soc. Lond. A, 337, 111-126.

Zoback, M.L., 1992. First-and second-order patterns of stress in the lithosphere: the world stress map project, J. geophys. Res., 97, 11 703-11 728.

\section{APPENDIX: MISFIT CALCULATION}

To quantify the misfit between the observed and modelled azimuth of $S_{\text {Hmax }}$, we first define the average observed azimuth $\bar{\beta}$ and the standard deviation $\overline{\Delta \beta}$ resulting from mean error in the individual data $\overline{\Delta \beta}_{\text {error }}$ and due to the spread of the data in a 'district' $\overline{\Delta \beta}_{\text {spread }}$ (Mardia 1972). Let $\beta_{i}$ be the $i$ th observation in a district with observation error $\Delta \beta_{i}$.

$$
\begin{aligned}
& w_{i}=1 / \Delta \beta_{i} \quad W=\sum_{i} w_{i}, \\
& \bar{c}=\left(\sum_{i} w_{i} \cos 2 \beta_{i}\right) / W \quad \bar{s}=\left(\sum_{i} w_{i} \sin 2 \beta_{i}\right) / W,
\end{aligned}
$$

Table A1. Magnitude of collisional forces along Eurasia southern boundary.

\begin{tabular}{lc}
\hline Colliding plate & Force magnitude $\left(\mathrm{TN} \mathrm{m}^{-1}\right)$ \\
\hline Africa & $1.0-2.5$ \\
Arabia & $1.3-2.7$ \\
India & $7.0-10.5$ \\
Australia & $0.0-1.3$ \\
\hline
\end{tabular}

$R=\sqrt{\bar{c}^{2}+\bar{s}^{2}} \quad \overline{\Delta \beta}_{\text {spread }}=\frac{1}{2} \sqrt{-2 \ln R} \quad \overline{\Delta \beta}_{\text {error }}=1 / W$,

$\bar{\beta}=\frac{1}{2} \operatorname{atan} 2(\bar{c}, \bar{s}) \quad \overline{\Delta \beta}=\sqrt{\overline{\Delta \beta}_{\text {error }}^{2}+\overline{\Delta \beta}_{\text {spread }}^{2}}$.

District size should be appropriate for the level of detail that can be resolved by the model.

In the $j$ th district, we compare the modelled stress azimuth $\alpha_{j}$ with $\bar{\beta}_{j}$. The average model misfit over the entire plate (consisting of $N$ districts) is

$\overline{\Delta \alpha}=\frac{1}{N} \sum_{j}^{N}\left|\alpha_{j}-\bar{\beta}_{j}\right|$

and the plate-wide average error in the data is

$\widehat{\Delta \beta}=\frac{1}{N} \sum_{j}^{N} \overline{\Delta \beta}_{j}$.

The same algorithm is used for subregions. 